\title{
Trabajo decente y sociedades cooperativas de trabajo asociado: Propuestas de implementación en la Ley 27/1999
}

\author{
David Gutiérrez Colominas ${ }^{1}$
}

Recibido: 3 de mayo de 2021 / Aceptado: 24 de junio de 2021 / Publicado: 2 de septiembre de 2021

Resumen. La implementación del trabajo decente es un desafío y oportunidad que los distintos países deben afrontar como consecuencia de su incorporación en el marco del Objetivo de Desarrollo sostenible número 8 de la Agenda 2030 para el Desarrollo Sostenible. Y ante esta situación, las sociedades cooperativas de trabajo asociado aparecen como actores ideales para materializar puestos de trabajo que conjuguen la salvaguarda y respeto de los derechos de las personas trabajadoras, la lucha contra la inseguridad en el trabajo, y la igualdad de oportunidades real entre hombres y mujeres, ofreciendo una alternativa ética y participativa que reduzca el desempleo y contribuya a la creación y mantenimiento de empleos de calidad. Sin embargo, el marco jurídico español de las sociedades cooperativas de trabajo asociado, previsto en la Ley 27/1999, se encuentra lejos de garantizar las distintas dimensiones del paradigma de trabajo decente, y requiere ser actualizado. En este contexto, el objetivo de este trabajo es ofrecer propuestas de reformulación legal de aquellos aspectos en el régimen jurídico estatal de las sociedades cooperativas de trabajo asociado más cercanos al paradigma del trabajo decente.

Para ello, este artículo examina el marco jurídico de las citadas sociedades, tanto desde una óptica constitucional como legal, concretando hasta qué punto es compatible la aplicación del concepto "trabajo decente" en las sociedades cooperativas de trabajo asociado. A continuación, se abordarán aspectos jurídicos regulados por el legislador en las sociedades cooperativas de trabajo asociado, ofreciendo propuesta de mejora o implementación en instituciones que deberían ser actualizadas a la luz del trabajo decente, como por ejemplo los anticipos societarios (art. 80.4 de la Ley 27/1999), la situación de prueba de las personas socias (art. 81 de la Ley 27/1999) y la configuración de las condiciones de trabajo (art. 83 de la Ley 27/1999), así como cuestiones que no han sido integradas en la propia norma, a saber, la igualdad de oportunidades entre hombres y mujeres y mecanismos de conciliación de la vida laboral y familiar.

Palabras clave: Trabajo decente; Objetivos de Desarrollo Sostenible; Sociedades cooperativas de trabajo asociado; Ley 27/1999.

Claves Econlit: K31; K22; O00.

\section{[en] Decent Work and Worker Cooperatives: Proposals for Implementation within the Framework of Law 27/1999}

\begin{abstract}
The implementation of decent work is a challenge and an opportunity that different countries must face as a consequence of its incorporation into the framework of the Sustainable Development Goal number 8 of the 2030 Agenda for Sustainable Development. In this scenario, worker cooperatives appear as ideal actors to materialize workplaces that combine the safeguard and respect for the workers rights, the fight against job insecurity, and real equal opportunities between men and women, offering an ethical and participatory alternative that reduces unemployment and contributes to the creation and maintenance of quality jobs. However, the Spanish legal framework for worker cooperatives, provided for by Law 27/1999, is far from guaranteeing the different dimensions of the decent work paradigm, and needs to be updated. In this context, the aim of this paper is to offer proposals, connected with decent work paradigm, for the legal reformulation of some aspects of worker cooperatives. To this end, this article examines the legal framework of these societies, both from a constitutional and legal perspective, specifying to what extent the application of the concept of "decent work" is compatible within the framework of worker cooperatives. Next, different dimensions of the decent work paradigm will be connected with legal aspects of worker cooperatives, offering proposals for improvement or implementation. Specifically, corporate advances (art. 80. 4 Law 27/1999), the probationary status of members (art. 81 Law 27/1999) and the configuration of working conditions (art. 83 Law 27/1999) and equal opportunities between men and women and mechanisms for reconciling work and family life will be examined.
\end{abstract}

Keywords: Decent Work; Sustainable Development Goals; Worker Cooperative; Law 27/1999.

Sumario. 1. Introducción: El trabajo decente como nuevo paradigma de desarrollo sostenible. 2. El marco jurídico actual de las sociedades cooperativas de trabajo asociado en el ordenamiento jurídico español. 3. La compatibilidad entre trabajo decente y

\footnotetext{
1 Universidad Autónoma de Barcelona, España.

Dirección de correo electrónico: david.gutierrez@uab.cat.
} 
sociedades cooperativas de trabajo asociado. 4. La implementación efectiva del trabajo decente en el marco jurídico de las sociedades cooperativas de trabajo asociado. 5. Conclusiones. 6. Referencias bibliográficas. 7. Referencias legales.

Cómo citar. Gutiérrez Colominas, D. (2021) Trabajo decente y sociedades cooperativas de trabajo asociado: Propuestas de implementación en la Ley 27/1999. REVESCO. Revista de Estudios Cooperativos, vol. $139, \quad$ e77442. https://dx.doi.org/10.5209/reve.77442.

\section{Introducción: El trabajo decente como nuevo paradigma de desarrollo sostenible}

Las cooperativas como instituciones de fomento socioeconómico han sido objeto de atención jurídica en diversas ocasiones. Desde la recomendación de la Organización Internacional del Trabajo (en adelante, OIT) núm. 127 sobre las cooperativas (1966), que fue reemplazada por la recomendación de la OIT núm. 193 sobre la promoción de las cooperativas (2002), se ha perseguido fomentar la expansión continuada, y no limitada a situaciones de crisis, del movimiento cooperativo global como alternativa viable y dinámica a la lógica de mercado (Molina Navarrete, C., 2014).

Los valores éticos propios de este modelo de organización empresarial, que pivotan sobre la participación responsable y democrática (Vergéz Sánchez, M., 1973), y que implican un alejamiento de los fundamentos del capitalismo (Valdés Dal-Re, F., 2010), se postulan como una alternativa a las sociedades de capital, que resultan especialmente atractivas en un escenario en el que priman la rentabilidad y la competitividad. En este sentido, las sociedades cooperativas aportan un marco de referencia basado en la propiedad conjunta, la solidaridad y la democracia, que ofrecen una forma de autoempleo no precaria, basada en la aportación personal de todos sus miembros al proyecto empresarial. De hecho, los valores de las sociedades cooperativas se manifiestan únicamente el seno de la propia organización empresarial, esto es, ad intra (Díaz De La Rosa, A., 2010). Así, cuando la cooperativa acude al mercado, lo hace en idénticas condiciones que el resto de los operadores económicos, $\mathrm{y}$, en consecuencia, los valores o principios éticos de este tipo de organizaciones empresariales no generan una desventaja económica. Este planteamiento es especialmente interesante en un contexto en el que confluyen la persistencia del desempleo, la desigualdad entre mujeres y hombres en el mercado de trabajo, la descentralización masiva de las estructuras productivas (Monereo Pérez, J.L., 2014) y la aparición de economías de plataformas (Arrieta Idiakez, F.J., 2019; Alfonso Sánchez, R., 2016), que ocasionan una degradación de la calidad del empleo (Considerando D de la Resolución del Parlamento Europeo, de 4 de julio de 2017, sobre las condiciones laborales y el empleo precario (2016/2221(INI). De hecho, la doctrina ya ha señalado la eficacia de las sociedades cooperativas para contribuir a corregir tres de los principales desequilibrios del mercado de trabajo -asalariado-: el paro masivo, la precariedad del empleo y la exclusión sociolaboral de ciertos colectivos de parados o de desempleados (Molina Navarrete, C., 2014; Hierro, F.J., 2003).

Ante estas circunstancias, el planteamiento jurídico de la mayoría de los países se ha centrado en orientar las regulaciones nacionales hacia formas de crecimiento sostenible que garanticen empleos de calidad a través del denominado trabajo decente, sin que ello suponga la pérdida de competitividad en estructuras productivas tradicionales. El concepto "trabajo decente" apareció por primera vez en la memoria del Director General presentada en la 87 $7^{\text {a }}$ reunión de la Conferencia Internacional del Trabajo "Trabajo decente" (junio de 1999), y constituye el punto de convergencia entre la promoción de los derechos fundamentales en el trabajo, el empleo, la protección social y el dialogo social (pág. 4). En particular, el trabajo decente es un paradigma que nace como instrumento para salvaguardar y respetar los derechos de las personas trabajadoras, luchar contra la inseguridad en el trabajo, reducir el desempleo y asumir una igualdad de oportunidades real entre hombres y mujeres. Se encarga de marcar un modelo de relaciones laborales que introduce un elemento cualitativo que vela por erradicar la precariedad laboral, si bien su calificación jurídica se incardina dentro de las denominadas manifestaciones de soft law, como consecuencia de su no inclusión en una norma internacional (Lozano Lares, F. y Salas Porras, M., 2017).

La apuesta institucional por el trabajo decente como estándar en los modelos de relaciones laborales se ha mantenido constante a lo largo de los últimos años, e incluso se ha conectado de forma explícita con el crecimiento sostenible. En concreto, la Resolución núm. 70/1 de la Asamblea General de la Organización de las Naciones Unidas "Transformar nuestro mundo: la Agenda 2030 para el Desarrollo Sostenible" (25 de septiembre de 2015, Ref.: A/RES/70/1, en adelante Resolución 70/1) contiene un total de 17 objetivos que comparten el desarrollo sostenible como pilar fundamental. De entre todos ellos, destaca el objetivo número 8, que constata la necesidad de promover el crecimiento económico sostenido, inclusivo y sostenible, el empleo pleno y productivo y el trabajo decente para todos. Y en esta misma línea, el informe de la OIT titulado "Trabajar para un futuro más prometedor" (2019) [en adelante, informe OIT 2019] constata la necesidad de incrementar la inversión en trabajo decente y sostenible en su apartado 2.3, a través de la implementación de un modelo empresarial centrado en las personas.

En un plano europeo, la Resolución del Parlamento Europeo, el Consejo y la Comisión de 17 de noviembre de 2017 (Ref: 2016/2095(INI) [en adelante, Pilar europeo de derechos sociales], también ha 
asumido los mismos valores que sustentan el desarrollo sostenible, a saber, igualdad de oportunidades, condiciones de trabajo justas y protección e inclusión social. A través de tres capítulos, denominados "igualdad de oportunidades y de acceso al mercado de trabajo", "condiciones de trabajo justas" y "protección e inclusión social", el pilar europeo de derechos sociales contempla un total de 20 principios que pretenden luchar contra la inseguridad económica y social, e insta a crear un futuro económico basado en el crecimiento sostenible y en una serie de principios y derechos esenciales para el buen y justo funcionamiento de los mercados laborales. Así, a título de ejemplo, la igualdad de género (principio 2), la igualdad de oportunidades (principio 3), el empleo seguro y adaptable (principio 5), información sobre las condiciones de trabajo y la protección en caso de despido (principio 7) o el dialogo social y participación de los trabajadores (principio 8) constituyen algunas premisas jurídicas fundamentales para la materialización del trabajo decente.

Ante este escenario, el desarrollo sostenible y el trabajo decente aparecen como nuevos estándares para garantizar empleos de calidad. Teniendo en cuenta que las sociedades cooperativas pueden desempeñar un papel fundamental como entes generadores de empleo (Hierro Hierro, F.J., 2003; García-Gutiérrez Fernández, C., 2001), y que simbolizan un régimen democrático de participación en la vida económica (Cabeza Pereiro, J., 2014), la conexión entre trabajo decente y sociedades cooperativas se presenta como idónea y debe ser una prioridad legal. Esta hipótesis, contribuiría a ofrecer un mayor atractivo a las sociedades cooperativas, cuyo éxito no ha acabado de despegar salvo contadas excepciones (Molina Navarrete, C., 2014: 57), y además, evitaría el fracaso a largo plazo de las sociedades cooperativas, como consecuencia de la imposición de un capitalismo que pretende sustituir los principios cooperativos por objetivos capitalistas y concentrar el capital en unas pocas organizaciones (Escribano Gutiérrez, J., 2010; Spear, R., 2004). Las características inherentes de las sociedades cooperativas, entre las que destacan la libre adhesión, la gestión democrática o la equidad en el reparto de beneficios, las convierte en una forma de organización empresarial orientadas hacia la transformación y el progreso social (García Jiménez, M., 2010), circunstancia que encaja perfectamente en las nuevas estrategias de desarrollo social internacionales y europeas. Ahora bien, el foco sobre el empleo obliga a centrar el objeto de este estudio sobre una de las modalidades de sociedad cooperativa prevista en la Ley 27/1999, de 16 de julio, de Cooperativas (en adelante, Ley 27/1999), a saber, las sociedades cooperativas de trabajo asociado (arts. 80 a 87), en las que existe coincidencia de las figuras de empresario/a y persona trabajadora y cuya finalidad es proporcionar a sus socios/as puestos de trabajo, a través de la organización en común de la producción de bienes o servicios para terceros.

En consecuencia, este artículo tiene el propósito de formular propuestas normativas de mejora sobre distintos aspectos regulados en el ámbito estatal de las sociedades cooperativas de trabajo asociado, con el objetivo de implementar las premisas sobre las que pivotan los conceptos "trabajo decente" y "desarrollo sostenible". Todo ello, a fin de garantizar que el trabajo en sociedades cooperativas de trabajo asociado es sinónimo de trabajo decente y contribuye a un desarrollo sostenible. Así, este trabajo parte de dos hipótesis: a) las sociedades cooperativas de trabajo asociado son un instrumento en el que puede implementarse el trabajo decente, como consecuencia de la aproximación normativa y judicial entre tales sociedades y la prestación de servicios por cuenta ajena; y, b) el marco jurídico estatal que regula las sociedades cooperativas de trabajo asociado (Ley 27/1999) requiere ser actualizado para integrar las distintas dimensiones del trabajo decente.

Metodológicamente, este estudio parte de una aproximación hermenéutica de los objetivos y metas de la Resolución núm. 70/1 y el pilar europeo de derechos sociales, todo ello en relación con el marco jurídico estatal, esto es la Ley 27/1999. Se excluye, en consecuencia, un examen autonómico de la cuestión, dada la dispersión normativa existente en la actualidad. Estas fuentes de carácter jurídico serán complementadas con una revisión bibliográfica y doctrinal sobre el régimen jurídico de las sociedades cooperativas de trabajo asociado.

La estructura del artículo parte de la definición de trabajo decente, y centraliza la discusión sobre las sociedades cooperativas de trabajo asociado. En primer lugar, se examinará el marco jurídico estatal de referencia, ofreciendo una visión constitucional y legal, así como las conexiones jurídicas que se han establecido, especialmente en el ámbito judicial, entre la prestación de servicios en las sociedades cooperativas de trabajo asociado y las relaciones laborales por cuenta ajena. En segundo lugar, se analizará si la aplicación del concepto "trabajo decente" es válido en el marco de las sociedades cooperativas de trabajo asociado, circunstancia esta que constituye la primera hipótesis del trabajo. Y, por último, se examinarán cuestiones concretas del marco legal de las citadas sociedades cooperativas, ofreciendo propuestas de mejora o implementación de aspectos concretos del paradigma del trabajo decente. Este último aspecto, que constituye la segunda hipótesis del trabajo, abordará tanto instituciones que deberían ser actualizadas, como por ejemplo los anticipos societarios (art. 80.4 de la Ley 27/1999), la situación de prueba de las personas socias (art. 81 de la Ley 27/1999) y la configuración de las condiciones de trabajo (art. 83 de la Ley 27/1999), como cuestiones que no han sido integradas en la propia norma, a saber, la igualdad de oportunidades entre hombres y mujeres y mecanismos de conciliación de la vida laboral y familiar. 


\section{El marco jurídico actual de las sociedades cooperativas de trabajo asociado en el ordenamiento} jurídico español

\subsection{Una visión introductoria constitucional}

La configuración jurídica de las sociedades cooperativas aparece sustentada en el ordenamiento jurídico español por el mandato constitucional contenido en el artículo 129.2 de la Constitución Española (en adelante, CE), y su materialización es fruto de la tradición y su consolidación política, económica y social en España (Calvo Ortega, R., 2003). Concretamente, este precepto constata el fomento, mediante una legislación adecuada, de las sociedades cooperativas por parte de los poderes públicos, que se suma a dos mandatos referidos a promover formas de participación en la empresa y establecer medios que faciliten el acceso de los trabajadores a la propiedad de los medios de producción.

Como puede observarse, la incardinación de este precepto en el Título VII permite señalar que nos encontramos ante una norma que impone deberes institucionales a los poderes públicos del Estado español, que no puede ser considerada un principio rector de la política social y económica (Díaz De La Rosa, A., 2010). Ello implica que el contenido de este precepto no puede ser clasificado como principio general del Derecho, si bien su eficacia interpretativa ha sido una cuestión controvertida. Así, Vida Soria, J. y Prados De Reyes, F.J., 1998 señalan que se limita a la mera consagración de postulados de carácter político-económico de escasa imperatividad normativa. Pero, en cambio, otros autores como Calvo Ortega, R., 2003 y Uriarte, R., 2004 han defendido una posición más protectora, señalando que el reconocimiento constitucional como mandato explícito concretado en el ámbito económico exige al Poder Judicial y al Tribunal Constitucional una interpretación de las normas infra constitucionales en pro de la promoción de las sociedades cooperativas. De hecho, incluso otros autores han señalado que se deriva un estatus jurídico privilegiado de las sociedades cooperativas sobre el resto de las empresas (véase el concepto "impacto valorativo", formulado por Vicent Chuliá, F., 2002) o que la referencia constitucional abarca también otro tipo de empresas encuadradas en la denominada "economía social" (Rojo Torrecilla, E. y Camas Roda, F., 2003). En mi opinión, la segunda tesis es la que aparece más alineada con el deseo del constituyente, y no por ello se pasa por alto los distintos grados de protección que confiere la constitución $e x$ artículo $53 \mathrm{CE}$, especialmente a la luz del artículo 5 de la Ley Orgánica 6/1985, de 1 de julio, del Poder Judicial, tal y como ha señalado Uriarte, R., 2004.

La formulación del artículo 129.2 CE permite detectar una estrecha conexión entre empleo y sociedades cooperativas que debe ser destacada. La coexistencia de la promoción de las sociedades cooperativas junto a la expresión "formas de participación en la empresa" no es baladí, y ha conducido a sostener que las sociedades cooperativas representan un mecanismo colectivizado de acceso a los medios de producción que identifica la participación de las personas trabajadoras con la propiedad de la empresa (Nogueira Guastavino, M., 2018; Díaz De La Rosa, A., 2010). Esta tesis es especialmente relevante en el caso de las sociedades cooperativas de trabajo asociado, que actúan como instrumento para ofrecer puestos de trabajo a sus socios, a través de la organización en común de la producción de bienes o servicios para terceros.

Sin embargo, la interrelación entre empleo y sociedades cooperativas está presente incluso extramuros del artículo 129.2 CE. En este punto, los artículos 35, 38 y $40 \mathrm{CE}$ son referencias claves que deben ser incluidas en la interpretación del artículo 129.2 CE, ya sea por su conexión con la configuración del Estado Social al amparo del art. 1 CE (Rojo Torrecilla, E. y Camas Roda, F., 2003) y la cláusula de igualdad real o concreción de la participación en la vida económica ex artículo 9.2 CE (Canalda Criado, S., 2019; Calvo Ortega, R., 2003; Uriarte, R., 2004; Vida Soria, J. y Prados De Reyes, F.J., 1998), o por el impulso que las sociedades cooperativas pueden ofrecer a fin de lograr la materialización efectiva del derecho al trabajo y el pleno empleo (Díaz De La Rosa, A., 2010; Arroyo Sánchez, P., 2003).

Otra característica que llama la atención del artículo 129.2 CE es el carácter programático con el que se instrumenta el fomento de las sociedades cooperativas. La configuración del citado precepto parte de la mención explícita de las sociedades cooperativas en el contexto de las formas de participación en la empresa, que no es incompatible con el principio de igualdad de trato entre empresas (Uriarte, R., 2004). Nos encontramos ante un reconocimiento del valor añadido de las sociedades cooperativas como instrumento para fomentar la integración ciudadana en la actividad económica (Vida Soria, J. y Prados De Reyes, F.J., 1998), y, por lo tanto, ante una clara apuesta constitucional de la potencialidad de las sociedades cooperativas como forma de organización empresarial. De hecho, el uso del tiempo futuro del verbo "fomentar" permite identificar una voluntad de protección con vocación de permanencia en el tiempo, que se concreta no sólo en el momento de la creación de las cooperativas, sino incluso en la protección legal del desarrollo de su actividad.

Sin embargo, el tenor literal del citado precepto ha suscitado diversas discusiones jurídicas de interés a propósito de su alcance y límites. En primer lugar, la ya señalada locución "[...] mediante una legislación adecuada [...]”, que pretendía eliminar la dispersión normativa que imperaba en la regulación de las sociedades cooperativas (Paz Canalejo, N., 1980, y de forma más extensa, Vicent Chuliá, F., 1979) y ofrecer 
una ventaja desde el plano patrimonial (Calvo Ortega, R., 2003), generó un debate a propósito del reparto de competencias entre el Estado y las Comunidades Autónomas. Si bien la primera materialización legal del citado precepto constitucional se produjo con la Ley 3/1987, de 2 de abril, General de Cooperativas (Ley 3/1987), derogada por la hoy vigente Ley 27/1999, de 16 de julio, de Cooperativas (Ley 27/1999), lo cierto es que la distribución competencial entre el Estado y las Comunidades Autónomas en materia de regulación sobre las sociedades cooperativas no se halla resuelta en el texto constitucional. El artículo 149.1 CE no contiene una reserva de modo directo y expreso de competencia exclusiva del Estado en materia de sociedades cooperativas, circunstancia esta que generó un escenario de proliferación normativa autonómica en materia de cooperativas.

Este escenario dio lugar a múltiples conflictos judiciales que obligaron al Tribunal Constitucional a pronunciarse sobre la naturaleza de la legislación sobre cooperativas. En otras palabras, si, en esencia, la regulación de las sociedades cooperativas podría calificarse como legislación mercantil, circunstancia esta que supondría la atribución de competencia exclusiva del Estado sobre esta materia ex artículo 149.1.6 CE. El mayor exponente de la posición adoptada por el Tribunal lo encontramos en la Sentencia del Tribunal Constitucional núm. 72/1983 de 29 de julio. Este pronunciamiento admite que el silencio constitucional del artículo 149.1 CE implica la inexistencia de una competencia exclusiva y, por lo tanto, las Comunidades Autónomas pueden regular la configuración jurídica de las cooperativas, siempre que la actividad societaria se desarrolle en el territorio autonómico, excluyendo expresamente el régimen jurídico de determinados actos y requisitos necesarios para la constitución formal de la sociedad por su naturaleza mercantil y aquellas cuestiones que presenten un manifiesto carácter laboral (Vida Soria, J. y Prados De Reyes, F.J., 1998). Esta posición judicial generó un cierto rechazo doctrinal, toda vez que la coexistencia forzada de regímenes jurídicos resulta ciertamente disfuncional (González Del Rey Rodríguez, I., 2008), constituye un obstáculo a la creación y crecimiento de sociedades cooperativas (García Jiménez, M., 2010) y genera situaciones problemáticas de ley aplicable para aquellas sociedades cooperativas que desarrollan su actividad en distintas Comunidades Autónomas (Alfonso Sánchez, R., 2009). De hecho, se ha llegado a considerar que la regulación autonómica de la cuestión cooperativa no procede, dada la naturaleza mercantil de las sociedades cooperativas (García-Gutiérrez Fernández, C., 1998), y afecta, incluso, al principio constitucional de unidad de mercado, al establecer soluciones jurídicas distintas par los mismos supuestos de hecho (Díaz De La Rosa, A., 2010).

En segundo lugar y último lugar, la mención expresa, y en exclusiva, a las sociedades cooperativas que contiene el artículo 129.2 CE ha planteado un debate ciertamente interesante a propósito de la preferencia constitucional de fomento de las sociedades cooperativas respecto a otras sociedades y los límites de este mandato. La cuestión tiene una cierta relevancia en la estructura y regulación de la actividad económica, ya que la constatación de las sociedades cooperativas en el citado precepto constitucional plantea una discusión en torno a qué sucede si una norma prioriza una forma de sociedad distinta a las cooperativas o si incluye criterios de selección que favorecen únicamente a las cooperativas. Afortunadamente, el Tribunal Constitucional ha tenido oportunidad de pronunciarse en dos ocasiones sobre el significado de la inclusión del término "cooperativas" en el marco del artículo 129.2 CE, ofreciendo un acertado canon de interpretación constitucional sobre la materia. Concretamente, las Sentencias del Tribunal Constitucional núm. 77/1985 de 27 de junio y núm. 103/1989 de 8 de junio sostienen que la preferencia por sociedades cooperativas frente a otro tipo de sociedades se admite de forma expresa por el artículo 129.2 CE, y no produce una diferencia de trato que merezca la calificación de discriminatoria, toda vez que se basa en un fundamento constitucional expreso. Sin embargo, esta doctrina impide identificar la promoción constitucional de las sociedades cooperativas con una ventaja incondicionada (Santiago Redondo, K., 2018), y, en consecuencia, no permite una priorización absoluta o incondicionada de las cooperativas. De hecho, conviene señalar que el artículo 129.2 CE no supone una obligación de promocionar en cualquier caso a las sociedades cooperativas, sino una mera posibilidad, que incluso puede no ser utilizada si así se considera oportuno, tal y como ha manifestado el Tribunal Constitucional en su Sentencia núm. 206/1997 de 27 de noviembre (F.J. XX).

\subsection{Un examen legal sobre la configuración de las sociedades cooperativas: especial consideración a las sociedades cooperativas de trabajo asociado}

El marco legal estatal vigente de las sociedades cooperativas lo encontramos en la Ley 27/1999, que supuso una reforma continuista del derecho de sociedades cooperativas respecto a la Ley 3/1987 y que actualizó el marco jurídico a las circunstancias económicas imperantes de la época. En efecto, los cambios en la realidad socioeconómica que representaron la entrada de España en la Unión Monetaria Europea, sumados a la proliferación de leyes autonómicas (Marín López, J., 1999), que fue una consecuencia lógica de la Sentencia del Tribunal Constitucional núm. 72/1983 de 29 de julio, ponían de relieve la conveniencia de actualizar el marco jurídico. Esta norma fue bien recibida por la doctrina, que la calificó como oportuna y necesaria, ya que aportó una mayor flexibilidad y respeto a la capacidad de autorregulación de las sociedades cooperativas 
(Pastor Sempere, C., 1999), así como nuevas tipologías societarias basadas en los principios cooperativos, (Paz Canalejo, N., 1999), entre otras virtudes.

En el ámbito sustantivo, la Ley 27/1999 introdujo mejoras significativas, como por ejemplo, la previsión de creación vía estatutaria de las secciones (art. 5), la disminución del número mínimo de socios (art. 8), la creación de dos categorías de socios: el socio, que equivale al socio usuario, y el socio colaborador, de carácter capitalista (arts. 12 a 18, y en especial, el art. 14), la flexibilización de la regulación de los órganos sociales de la cooperativa (Art. 19); la regulación de nuevos tipos de cooperativa (arts. 105 a 107), la obligación de auditar las cuentas anuales en los supuestos así exigidos legalmente (art. 62), entre otras (Blanco Morales, J., 2000; Alonso Rodrigo, E., 1999; Marín López, J., 1999; Pastor Sempere, C., 1999b).

En otro orden de cosas, la Ley 27/1999 mantiene la apuesta por dedicar una serie de artículos exclusivos a las sociedades cooperativas de trabajo asociado, tendencia esta iniciada en la Ley 3/1987. En este sentido, las sociedades cooperativas de trabajo asociado están reguladas actualmente en los artículos 80 a 87 de la Ley $27 / 1999$, y se definen como aquellas que tienen como objetivo proporcionar puestos de trabajo a sus socios a través del desarrollo de actividades económicas empresariales. La creación y mantenimiento de empleo estable para los socios constituye una premisa para estas sociedades cooperativas (Rodríguez Santos, E., 2018; Espín Sáez, M., 2009; Rojo Torrecilla, E. y Camas Roda, F., 2003), ofreciendo un marco jurídico de protección para las personas socias-trabajadoras (Santiago Redondo, K., 1999). De hecho, es especialmente relevante en las sociedades cooperativas de trabajo asociado, dado que ofrece un mecanismo para superar el modelo convencional de relaciones laborales (Paz Canalejo, N., 1982), y se aparta de la dualidad trabajo por cuenta propia y por cuenta ajena. Sin embargo, la configuración legal de las relaciones que acontecen en el marco de la cooperativa merece legalmente distintas calificaciones, aunque la prestación de servicios pueda ser coincidente o idéntica (Vila Tierno, F., 2014), en función de si la persona ostenta o no la cualidad de socio/a.

Concretamente, la relación de las personas socias con la cooperativa de trabajo asociado será considerada como societaria por imperativo legal, al amparo del artículo 81 de la Ley 27/1999, si bien la propia norma concreta aspectos específicos sobre cómo se desarrolla la prestación de servicios. La calificación expresa de la naturaleza de la relación, que fue una novedad de la Ley 27/1999 respecto de la Ley 3/1987, de 2 de abril, General de Cooperativas, ha sido una cuestión ampliamente discutida por la doctrina en los últimos años, incluso de forma previa a la entrada en vigor de la Ley 27/1999. En efecto, la existencia, de facto, de una prestación de servicios que cumple la mayoría de los requisitos del artículo 1 del Real Decreto Legislativo $2 / 2015$, de 23 de octubre, por el que se aprueba el texto refundido de la Ley del Estatuto de los Trabajadores (en adelante, TRLET) ha generado la existencia de distintas corrientes doctrinales. Una primera posición ha defendido la calificación de la relación entre persona socia trabajadora y cooperativa como estrictamente laboral (Santiago Redondo, K., 1998; Pedrajas Pérez, F. y Prados De Reyes, F.J., 1975), partiendo de un precedente normativo, a saber, la Orden de 17 junio de 1947, que calificó a todas las personas que prestaban servicios en las sociedades cooperativas como personas trabajadoras por cuenta ajena, tal y como señala Luján Alcaráz, J., 1999. Una segunda posición se ha inclinado por el reconocimiento únicamente de una relación societaria entre personas socias y sociedad cooperativa, atendiendo a la ausencia de indicios claves en la apreciación de la ajenidad y dependencia (Sagardoy Bengoechea, J.A., 1964; Valdés Dal-Re, F., 1980), e incluso, a sensu contrario, se ha señalado que afirmar la existencia de ajenidad sin eliminar la responsabilidad de las personas socias por las pérdidas es técnicamente contradictorio (Ortiz Lallana, M.C., 1989).

La tercera y última tesis sostiene una visión mixta de la cuestión, apuntada por Montoya Melgar, A., 1980 y materializada judicialmente por primera vez en la Sentencia del Tribunal Supremo núm. 989/1987 de 19 de mayo, cuya doctrina ha perdurado en el tiempo hasta la actualidad. En concreto, la tesis del Tribunal Supremo parte de la peculiar condición jurídica de la persona socia-trabajadora, que justifica la estimación del carácter mixto de su estatus jurídico, a caballo entre la relación societaria impuesta legalmente y la prestación de una actividad de trabajo bajo la óptica de la jurisdicción social.

Aunque esta visión pueda parecer técnicamente ajena al planteamiento del legislador, lo cierto es que la competencia para conocer las cuestiones litigiosas derivadas de la prestación de servicios entre las sociedades laborales o cooperativas de trabajo asociado, y sus socios trabajadores ha correspondido tradicionalmente a la jurisdicción social desde la Ley 3/1987. En consecuencia, las diferentes normas procesales laborales han sido tributarias de este planteamiento, prácticamente desde el artículo 2.o del Real Decreto Legislativo 521/1990 hasta el actual artículo 2.c de la Ley 36/2011, de 10 de octubre, reguladora de la jurisdicción social (en adelante, LRJS). Ello supuso, inicialmente, una fuente judicial de inseguridad por la existencia de criterios contradictorios (Valdés Dal-Re, F., 2010), resuelta de forma progresiva por la Sala Social del Tribunal Supremo, que ha unificado la cuestión a lo largo de los años. Y, de hecho, incluso se aprecia a lo largo de los últimos años una tendencia expansiva que pretende integrar aspectos tuitivos propios del derecho al trabajo en las relaciones entre cooperativa y socios trabajadores. Así, a título de ejemplo, véase la aplicación de la doctrina judicial del levantamiento del velo en supuestos de utilización fraudulenta de sociedades cooperativas de trabajo asociado, aplicando la protección prevista para situaciones de cesión 
ilegal de trabajadores (Sentencia del Tribunal Supremo núm. 549/2018. de 18 de mayo - Rec. 3513/2016), o el encuadramiento de las personas socias de sociedades cooperativas de trabajo asociado en el Régimen General de Seguridad Social y el acceso a la protección social que ofrece el sistema de Seguridad Social, destacando especialmente el acceso a la jubilación anticipada como consecuencia de la extinción del contrato de trabajo como consecuencia del acuerdo adoptado por la Asamblea General de la propia cooperativa (Sentencias del Tribunal Supremo de 20 de noviembre de 2018, 19 de diciembre de 2018 y 7 de febrero de 2019 - Recs. 3407/2016, 2233/2017 y 649/2017, respectivamente). Sin embargo, el ejemplo más paradigmático de esta tendencia se halla en la Sentencia del Tribunal Supremo núm. 347/2019 de 8 de mayo (Rec. 42/2018), que reconoce la existencia y ejercicio de derechos de participación colectiva (en particular, libertad sindical - art. $28 \mathrm{CE}$ ) a los socios trabajadores de sociedades cooperativas de trabajo asociado. A tenor de la amplitud del citado precepto constitucional, del artículo 2.c LRJS, el convenio de la OIT núm. 98 sobre el derecho de sindicación y de negociación colectiva (1949) y la recomendación de la OIT núm. 193 sobre la promoción de las sociedades cooperativas (2002), esta sentencia ha supuesto un gran paso en la aproximación jurídica entre trabajadores y socios trabajadores en materia de derechos, y cuyo reconocimiento ya venía exigiendo la doctrina iuslaboralista con anterioridad (Cabeza Pereiro, J., 2014; Escribano Gutiérrez, J., 2010).

Al debate judicial se suman variantes normativas adoptadas en sede autonómica que han merecido la creación de una nueva denominación, a saber, "autoempleo asociado" (Cuevas Gallegos, J., 2011), y que evidencian la vigencia de este debate. En concreto, Rodríguez Santos, E., 2018:58-59 indica la coexistencia de dos paradigmas que conciben el requisito de subordinación de forma distinta. Por un lado, la Ley 27/1999, y las normas autonómicas sobre sociedades cooperativas de las Comunidades de Castilla y León, Extremadura, Galicia, La Rioja, Madrid y Navarra, que conciben la sociedad cooperativa de trabajo asociado como un motor de creación de empleo que proporciona puestos de trabajos a las personas socias, adoptando una posición más pasiva que acerca la prestación de servicios de aquellas a la figura de las personas trabajadoras por cuenta ajena. Por otro lado, la regulación de Comunidades Autónomas como Andalucía, Aragón, Asturias, Baleares, Cantabria, Castilla-La Mancha, Cataluña, Comunidad Valenciana, Murcia y País Vasco, que optan por una visión que ofrece una mayor libertad a las personas socias, y que ha sido calificada por Rodríguez Santos, E., 2018 como una posición, por tanto, más cercana a la persona trabajadora autónoma asociada, esto es, al emprendimiento colectivo.

En cualquier caso, la naturaleza de la relación persona socia trabajadora y sociedad cooperativa no impide que las sociedades cooperativas puedan realizar contrataciones de personas no socias que presten servicios por cuenta ajena en el desarrollo de la actividad económica, si bien atenta, en cierta manera, contra la lógica propia de estas sociedades (Alonso Soto, F., 1984). Este tipo de relaciones supondrá la existencia de una relación laboral entre la sociedad cooperativa y la persona en cuestión, siempre que se cumplan los requisitos del artículo 1 TRLET. Así, en estas situaciones, el marco jurídico de aplicación será la legislación laboral común, sin ninguna ampliación o modificación del reconocimiento o ejercicio de derechos y obligaciones de las personas que prestan servicios por cuenta ajena, salvo situaciones muy concretas de representación colectiva como la prevista en el párrafo cuarto del artículo 33 de la Ley 27/1999.

Entrando a examinar la configuración legal específica de este tipo de sociedades cooperativas, la prestación de servicios presenta un carácter dual, ya expuesta previamente, a saber, la prestación de servicios entre personas socias trabajadoras y cooperativa y aquellos sujetos que presten servicios para la cooperativa sin ostentar la condición de socios/as. La Ley 27/1999 centra sus esfuerzos, de manera lógica, en regular los derechos, obligaciones y límites de la relación jurídica entre socio/a trabajador/a y cooperativa, excluyendo así la intervención normativa en el resto de las situaciones de carácter laboral, que exigirán la aplicación del TRLET, excepto en materia de jornada máxima anual, que vendrá limitada, salvo excepciones, por el 30 por 100 del total de horas/año realizadas por los socios trabajadores ex art. 80.7 de la Ley 27/1999. Así, los artículos 80 a 87 de la Ley 27/1999, regulan una gran variedad de cuestiones nucleares relativas a la prestación de servicios de las personas socias trabajadoras, que incluyen desde el derecho a obtener percepciones periódicas de carácter no salarial a cuenta de los excedentes (art. 80.4); la prohibición de trabajos nocturnos a menores de 18 años (art. 80.6 de la Ley 27/1999), la situación de prueba a las personas recién incorporadas (art. 81 de la Ley 27/1999); la configuración de la jornada, descansos semanales, fiestas, vacaciones (art. 83 de la Ley 27/1999); el régimen de suspensiones y excedencias (art. 84 de la Ley 27/1999) o hasta el régimen disciplinario aplicable (art. 82 de la Ley 27/1999), entre otras.

A este marco jurídico debe sumársele el papel que desempeña el denominado reglamento de régimen interno, definido legalmente como un instrumento de desarrollo de los estatutos (art. 11.4 Ley 27/1999), y que el legislador ha priorizado, por ejemplo, frente a la aplicación de referencias geográficas en el marco de la determinación de la cuantía de los anticipos laborales (artículo 118.4 de la Ley 3/1987, que contiene la referencia "en la zona y sector de actividad"). Este instrumento jurídico asume un papel muy destacado en la concreción de cuestiones relacionadas con la prestación de servicios. Concretamente, se encargará de regular el régimen disciplinario (art. 82 de la Ley 27/1999), ampliar los supuestos de permiso, su tiempo de duración y la atribución de su carácter retribuido (art. 83 de la Ley 27/1999) y la posibilidad de conceder excedencias 
voluntarias a los socios trabajadores (art. 84 de la Ley 27/1999). En consecuencia, el reglamento de régimen interno actúa como mecanismo de regulación que permite adaptar las condiciones de trabajo al planteamiento organizativo de la sociedad cooperativa, actuando, tal y como señala Escribano Gutiérrez, J., 2010, como sustituto de la regulación sectorial que aporta el convenio colectivo en las relaciones laborales.

Como puede observarse, el legislador ha configurado un marco jurídico que apuesta por integrar, de manera equilibrada, un marco jurídico tuitivo, manifestado en la previsión de algunas normas de carácter legal de derecho mínimo necesario y no disponibles por los estatutos, el reglamento de régimen interno o la Asamblea General, calificados por la doctrina incluso como irrenunciables por el propio socio trabajador (Valdés Dal-Re, F., 2010), que a su vez ofrezca espacios de regulación propios y diferenciadores de la idiosincrasia colectiva de la sociedad cooperativa de trabajo asociado. Así, la duración del periodo de prueba cuando así se prevea (art. 81 de la Ley 27/1999) y las situaciones de suspensiones y excedencias (art. 84 de la Ley 27/1999), son claros ejemplos de espacios normativos sin posibilidad de modificaciones en el seno de la cooperativa, que se contraponen a cómo puede acceder cualquier persona a la condición de socio/a trabajador/a (art. 80.8 de la Ley 27/1999), el régimen disciplinario aplicable (art. 82 de la Ley 27/1999), la obligatoria aplicación de las normas sobre salud laboral y prevención de riesgos laborales (art. 80.5 de la Ley 27/1999) o el sometimiento de las cuestiones contenciosas al orden jurisdiccional social (art. 87 de la Ley 27/1999). Estos ejemplos ilustran una voluntas legislatoris intervencionista fuertemente debilitada (Cabeza Pereiro, J., 2014; Valdés Dal-Re, F., 2010), que pretende ofrecer un régimen de garantías mínimo, sin que ello implique una renuncia absoluta del poder de autoorganización de las condiciones de trabajo en un modelo de sociedad en el que las personas trabajadoras son, a su vez, también propietarias.

\section{La compatibilidad entre trabajo decente y sociedades cooperativas de trabajo asociado}

Las sociedades cooperativas de trabajo asociado constituyen el escenario ideal para el fomento del empleo desde una perspectiva no precaria. Ya no sólo por su contextualización en el marco de las sociedades cooperativas, que constituye una organización empresarial caracterizada por un equilibrio de poder económico (García-Gutiérrez Fernández, C., 2001), por su carácter asociativo o su naturaleza de instrumento colectivo de autoempleo (González Del Rey Rodríguez, I., 2008), sino por la separación del conflicto perpetuo que supone la contraposición de intereses entre empresa y personas trabajadoras. En efecto, el carácter personal de la unión entre las personas socias en las sociedades cooperativas de trabajo asociado, en la que confluye la prestación de servicios, la propiedad de los medios de producción y la organización de la actividad económica excluye la imposición de una dimensión exclusivamente económica que anule o reduzca los derechos de las personas trabajadoras. El objetivo último no es tanto lograr la máxima plusvalía derivada de la explotación del capital sino proporcionar puestos de trabajo a las personas socias. Así, el interés por maximizar el beneficio económico empresarial no es un factor que entre en conflicto directo con las condiciones de la prestación de servicios, y, por lo tanto, existe un riesgo muy bajo de sobreponerse sobre las condiciones de trabajo.

Sin embargo, ¿qué conexión existe entre precariedad y trabajo decente? En otras palabras, ¿la no precariedad en el empleo es sinónimo de trabajo decente? Cómo ya se ha visto en el apartado inicial de este estudio, la definición de trabajo decente reivindica la salvaguarda y respeto de los derechos de las personas trabajadoras, y ofrece mecanismos de lucha contra la inseguridad en el trabajo y el desempleo, entre otros. En particular, el informe de la OIT "El empleo atípico en el mundo" (2016) [en adelante, informe OIT 2016], en su pág. 3, definió trabajo decente a través de distintos elementos, que incluyen la oportunidad de acceder a un empleo productivo que genere un ingreso justo, la seguridad en el lugar de trabajo y la protección social para las familias, mejores perspectivas de desarrollo personal e integración social, libertad para que los individuos expresen sus opiniones, se organicen y participen en las decisiones que afectan sus vidas, y la igualdad de oportunidades y trato para todos, mujeres y hombres. La pretensión básica del "trabajo decente" es luchar contra las desigualdades propias que se generan en el marco de las relaciones laborales, que han sido agravadas por la estandarización de la globalización. Para ello, se abordan distintos planos o pilares, que incluyen la creación de empleo, la garantía de los derechos laborales o la existencia del diálogo social, entre otras cuestiones, y que han sido concretadas en distintos indicadores por la doctrina, como la seguridad del mercado de trabajo, la estabilidad en el empleo, la seguridad profesional (Figueiredo, J., Bonnet, F. y Standing, G., 2003); el volumen de ingresos, la jornada laboral, el desempleo, el desnivel entre las tasas de actividad masculina y femenina (Bescond, D., Châtaignier, A. y Mehran, F., 2003); la conciliación de la vida laboral y familiar, la protección social (Anker, R., Chernyshev, I., Egger, P., Mehran, F. y Ritter, J., 2003), entre otros.

Las referencias a la precariedad, en cambio, se concretan sobre formas de empleo que no cumplen las normas y leyes nacionales, internacionales y de la Unión Europea, o que no ofrecen recursos suficientes para una vida digna o una protección social adecuada, tal y cómo se ha definido en el apartado I.3 de la Resolución del Parlamento Europeo, de 4 de julio de 2017, sobre las condiciones laborales y el empleo 
precario (2016/2221(INI) [en adelante, Res. de 4 de julio de 2017]. En consecuencia, la existencia de precariedad está condicionada no sólo por la modalidad contractual y un uso fraudulento de la misma, sino también por la existencia de un marco legal insuficiente respecto a la regulación de las condiciones de trabajo, tales como la remuneración, el horario, las funciones del puesto de trabajo, la no discriminación o la seguridad y salud, entre otras.

La puesta en común de ambas definiciones permite observar que el trabajo decente surge como una respuesta sobre cómo afrontar la precariedad de forma homogénea a través de indicadores absolutos (Anker, R. et al., 2003), y, de hecho, la ausencia de precariedad no es sinónimo de trabajo decente. En efecto, el trabajo decente abarca diversas dimensiones que van más allá de solventar el incumplimiento de los estándares legales mínimos en las relaciones laborales, lo que aleja ambos conceptos y conecta el trabajo decente con la caracterización europea de la expresión "calidad del empleo" (Merlié, D. y Paoli, P., 2000). Y es precisamente esta circunstancia la que sitúa el trabajo decente como una herramienta ideal en el marco de las sociedades cooperativas, cuyas problemáticas no están tan conectadas con el incumplimiento del marco legal, sino con la necesidad de abrir nuevos horizontes normativos, que reivindiquen la finalidad social de las sociedades cooperativas e incrementen su atractivo jurídico.

Así, la cuestión central que debe abordarse en este momento es si la aplicación del concepto "trabajo decente" en términos jurídicos es posible en el marco de las sociedades cooperativas de trabajo asociado, y en su caso, cómo podría implementarse por el legislador. Tal y cómo ya se ha señalado previamente, la Ley 27/1999 y su interpretación por los tribunales ha generado un escenario en el que existen relaciones societarias ex artículo 80.1 de la Ley 27/1999 que presentan características propias de las relaciones laborales. Así, ¿la naturaleza societaria impide la implementación del trabajo decente en este tipo de sociedades cooperativas? Un examen a las distintas resoluciones que caracterizan el trabajo decente permite afirmar que la calificación del vínculo no es una cuestión determinante para su existencia y la aplicación de sus principios. Tanto el objetivo número 8 de la Resolución núm. 70/1, el informe OIT 2016, el apartado 2.3 del informe OIT 2019, como el Pilar europeo de derechos sociales y la Res. de 4 de julio de 2017 comparten un enfoque basado en el empleo y sus condiciones, que incluye, tal y como ha señalado Ghain, D., 2003, los trabajadores de la economía regular, los trabajadores asalariados de la economía informal, los trabajadores autónomos y los que trabajan a domicilio.

Por lo tanto, el factor primordial es la prestación de servicios, y, en consecuencia, el vínculo jurídico no es un elemento relevante para la aplicación del paradigma de trabajo decente. Y en este sentido, en las sociedades cooperativas de trabajo asociado existe una prestación de trabajo sujeta al ámbito de organización y dirección de la sociedad cooperativa, bien realizada por la persona socia trabajadora tal y como ha señalado el fundamento de derecho V.2 de la Sentencia del Tribunal Supremo de 8 de mayo de 2019 (Rec. 42/2018), o bien efectuada por personas contratadas por la propia sociedad. En suma, la calificación del vínculo jurídico no es una cuestión determinante para la existencia y la aplicación de los principios del trabajo decente y, por lo tanto, no existe obstáculo normativo para su implementación en el marco de las sociedades cooperativas de trabajo asociado

\section{La implementación efectiva del trabajo decente en el marco jurídico de las sociedades cooperativas de trabajo asociado}

Teniendo en cuenta las posibilidades que ofrece el paradigma del trabajo decente, es de interés indicar qué aspectos de la regulación legal de las sociedades cooperativas de trabajo asociado podrían ser modificados para encajar sus objetivos o pilares fundamentales en la regulación de las citadas sociedades cooperativas. De hecho, la implementación efectiva del trabajo decente se suma a la necesidad de proceder a actualizar el marco jurídico de las sociedades cooperativas, dado que la Ley 27/1999 no ha experimentado modificaciones sustanciales desde prácticamente 2015. Su actualización podría incluir, además de la implementación de los estándares del trabajo decente, la adaptación de la configuración de las sociedades cooperativas a la economía colaborativa (Arrieta Idiakez, F.J., 2019; Alfonso Sánchez, R., 2016), entre otras modificaciones que por razones de afinidad temática no serán abordadas en este artículo.

A fin de sistematizar las distintas propuestas de implementación del trabajo decente en el marco jurídico de las sociedades cooperativas de trabajo asociado, se tomarán como referencia, desde un punto de vista metodológico, los cuatro objetivos estratégicos de este paradigma, a saber, la promoción de los derechos fundamentales en el trabajo; el empleo; la protección social y el diálogo social, todos ellos indicados en la memoria del Director General de la OIT en el marco de la $87^{a}$ reunión (junio 1999), y su concreción en el marco del objetivo de desarrollo sostenible número 8 de la Resolución núm. 70/1 y en el apartado 9 de la Res. de 4 de julio de 2017.

De esta manera, los siguientes apartados del trabajo examinarán aspectos normativos de las sociedades cooperativas de trabajo asociado que requieren una intervención jurídica más inmediata como consecuencia de las distintas dimensiones que componen el paradigma del trabajo decente. En particular, serán objeto de 
tratamiento los anticipos societarios como manifestación del carácter productivo de la prestación de servicios (art. 80.4 de la Ley 27/1999), la situación de prueba de las personas socias como mecanismo para garantizar oportunidades de empleo estable (art. 81 de la Ley 27/1999), la configuración de las condiciones de trabajo y su conexión con las condiciones de libertad en el empleo (art. 83 de la Ley 27/1999), y, por último, la igualdad de oportunidades entre hombres y mujeres en el seno de las sociedades cooperativas de trabajo asociado.

\subsection{La necesaria actualización de los anticipos societarios como manifestación del carácter productivo de la prestación de servicios}

La naturaleza productiva de las funciones desarrolladas en el marco de las sociedades cooperativas objeto de estudio lleva aparejada la percepción, por parte de las personas socias, de cantidades económicas como consecuencia de su vinculación. La más característica en el marco de las sociedades cooperativas de trabajo asociado es la prevista en el artículo 80.4 de la Ley 27/1999, que contempla los denominados anticipos societarios, cantidades estas que se suman a las percepciones previstas para el resto de las modalidades de sociedades cooperativas, como son el devengo de intereses por las aportaciones obligatorias al capital social (art. 48 de la Ley 27/1999) y al reembolso de las cantidades en caso de baja de la sociedad cooperativa (arts. 51 y 75 de la Ley 27/1999).

La figura de los anticipos societarios se diseña como una serie de percepciones periódicas, a cuenta de los excedentes de la cooperativa, a percibir según la participación de la persona en la actividad cooperativizada. Es, por lo tanto, la verdadera medida de la implicación del socio trabajador en la dimensión económica de la sociedad (Espín Sáez, M., 2009). Si bien el propio precepto señala explícitamente que no tienen la consideración de salario, distintas circunstancias previstas legalmente conducen a apreciar similitudes entre ambas. Así, el periodo de percepción, que se fija en un plazo no superior a un mes (art. 80.4 de la Ley 27/1999), su devengo por la prestación de trabajo a razón de la participación de la persona socia en la actividad de la sociedad cooperativa (Art. 80.4 de la Ley 27/1999), y su percepción incluso durante los periodos de vacaciones anuales y los días festivos (Art. 83.1.d de la Ley 27/1999) son características ciertamente semejantes al salario.

Ante este escenario, la cuestión central que conecta los anticipos societarios y el trabajo decente no es tanto su posible calificación como salario, disquisición esta ya examinada previamente por la doctrina (López Gandía, J., 2006; Ortiz Lallana, M.C., 1989; Valdés Dal-Re, F., 1975) sino concretar si el régimen jurídico de los anticipos societarios garantiza un medio de subsistencia aceptable para las personas socias. Y en este punto, el esquema legal de los anticipos societarios presenta problemas de compatibilidad con el trabajo decente, ya que asegura una percepción en el tiempo, pero no se pronuncia a propósito de un valor mínimo de su cuantía. Este hecho es especialmente importante desde la óptica del trabajo decente, ya que la Ley 27/1999 diseña las sociedades cooperativas de trabajo asociado como instrumentos societarios en los que la implicación económica de las personas socias no está conectada con la aportación al capital social, sino con la aplicación de los esfuerzos personales al objeto social (Espín Sáez, M., 2009). Así, los ingresos de las personas socias proceden de las funciones realizadas en el marco de la actividad cooperativizada, siendo económicamente dependientes del trabajo que se realiza en la cooperativa (García Jiménez, M., 2015), y por lo tanto, el marco jurídico actual no garantiza que las percepciones sean suficientes para garantizar unos ingresos dignos. De hecho, la cuestión tiene un impacto muy trascendental en la esfera económico-personal de la persona socia incluso una vez ha finalizado el vínculo con la sociedad cooperativa. En efecto, los importes percibidos en concepto de anticipos societarios afectarán a las bases de cotización de la persona en cuestión, cuantías estas cuyo valor es clave a efectos de determinar el monto de futuras prestaciones de la Seguridad Social. Sin embargo, la facultad de determinar qué conceptos deben integrar la base de cotización de las personas socias y de declarar la cuantía de los anticipos societarios corresponde, ante el silencio de la Ley 27/1999, a las propias sociedades cooperativas (Rodríguez Santos, E., 2018), circunstancia esta que no ofrece garantías legales de garantizar medios de subsistencia suficientes a futuro.

A esta circunstancia, debe sumarse otro elemento no menor que refuerza la necesidad de regular las cuantías de los anticipos societarios, a saber, la posible utilización fraudulenta de las sociedades cooperativas de trabajo asociado por razones competitivas. El contexto en el que se produce la actividad económica de la sociedad cooperativa no es ajeno o separado al de otro tipo de sociedades. Y ello implica, para el resto de los agentes que no pertenecen a la categoría de sociedades cooperativas de trabajo asociado, el sometimiento al cumplimiento de los límites legales previstos en materia salarial. En concreto, ello se traduce en la sujeción a una remuneración que alcance el salario mínimo interprofesional y la previsión de tablas salariales en los convenios colectivos de aplicación. Ante este escenario, la ausencia de una asignación cuantitativa de carácter mínimo en materia de anticipos societarios puede conducir a utilizar de forma fraudulenta las sociedades cooperativas de trabajo asociado. Si bien esta problemática fue advertida y solventada por el legislador en el artículo 48.5 de la Ley 52/1974, de 19 de diciembre, General de Cooperativas, a través de la descalificación de la sociedad cooperativa en caso de anticipos laborales inferiores al salario mínimo 
interprofesional en cómputo anual durante un periodo superior a dos años, la desaparición de esta regla ha generado situaciones de uso fraudulento a través de la figura de los "falsos autónomos", tal y cómo ha señalado Molina Navarrete, C., 2014:82. El silencio de la Ley 27/1999 ha intentado ser compensado por la jurisprudencia en distintas ocasiones, siendo el exponente más reciente y revolucionario la Sentencia del Tribunal Supremo de 18 de mayo de 2018 (Rec. 3513/2016). Este pronunciamiento judicial avanzó un paso más en la línea iniciada por la Sentencia de Tribunal Supremo de 17 de diciembre 2001 (rec. 244/2001), e instauró la atribución de la carga de la prueba de la naturaleza real de la actividad a la sociedad cooperativa. Sin embargo, el papel de los tribunales es especialmente limitado ante la falta de previsión de mecanismos legales, que se suma a la ausencia de actualización de la Ley 27/1999 a los nuevos paradigmas del trabajo basados en la descentralización y subcontratación.

Por todo ello, sería conveniente abordar una modificación del actual artículo 80.4 de la Ley 27/1999 que suponga una aproximación al paradigma del trabajo decente en términos económicos. A modo de sugerencia, sería interesante que el referido precepto reconociera una cuantía mínima tomando como modelo el importe, en cómputo anual, del salario mínimo interprofesional, recuperando así la regla prevista en el artículo 48.5 de la Ley 52/1974, de 19 de diciembre, General de Cooperativas. De hecho, este planteamiento se ha resistido a desaparecer pese al silencio adoptado por el legislador estatal, y ha sido incluso retomado por algunas normas autonómicas, tal y cómo han señalado López Gandía, J., 2006 y Rodríguez Santos, E., 2018. Esta propuesta podría ser complementada con un mandato normativo que obligase a tomar como referencia mínima las tablas salariales contenidas en el convenio colectivo aplicable a la actividad económica cooperativizada, tal y cómo ya señaló Espín Sáez, M., 2009, a fin de evitar un uso fraudulento de las sociedades cooperativas. De esta manera, el salario mínimo interprofesional actuaría como garantía general para todas las sociedades cooperativas de trabajo asociado, y en caso de existir, los importes previstos en las tablas salariales de los convenios colectivos de aplicación reforzarían la percepción de unos ingresos suficientes para garantizar la subsistencia tanto actual cómo futura de las personas socias.

\subsection{La situación de prueba de las personas socias como mecanismo para garantizar oportunidades de empleo estable}

Las ventajas que ofrecen las sociedades cooperativas de trabajo asociado como mecanismo de creación de empleo ya se han apuntado a lo largo de este artículo y son especialmente positivas al aunar los valores propios de estas sociedades. Sin embargo, desde el plano jurídico, la creación de puestos de trabajo en el seno de las sociedades cooperativas de trabajo asociado puede alinearse de forma más eficaz con los valores propios del trabajo decente. Y toda vez que las sociedades de trabajo asociado tienen como objetivo proporcionar puestos de trabajo a sus socios, al amparo del artículo 80.1 de la Ley 27/1999, el objetivo principal del legislador con relación a esta faceta del trabajo decente debe centrarse en mejorar aspectos del acceso y admisión a la condición de persona socia.

La integración en una cooperativa de trabajo asociado exige una doble aportación: a) la aportación obligatoria al capital social que corresponda según los estatutos y el abono de la cuota de ingreso correspondiente, de conformidad con el artículo 13.5 de la Ley 27/1999; y b) la aportación de trabajo personal y directo en la actividad económica. Formalmente, el artículo 13 de la Ley 27/1999 exige formular por escrito una solicitud al Consejo Rector, que deberá responder forma argumentada mediante acuerdo en un plazo máximo de 3 meses, y contempla, en su apartado 2, la posibilidad de recurrir la hipotética inadmisión.

No obstante, el artículo 81 de la Ley 27/1999 contempla la posibilidad de admisión de la persona socia en situación de prueba, siempre que los estatutos así lo prevean, que implicará los mismos derechos y obligaciones que el resto de las personas socias trabajadoras, con las salvedades previstas en el apartado 3 del artículo 81 de la Ley 27/1999, entre las que se incluye no estar facultadas a hacer aportaciones al capital social ni desembolsar la cuota de ingreso. Con carácter general, su duración no será superior a seis meses (art. 81.2 de la Ley 27/1999), si bien podrá ampliarse hasta dieciocho meses en los puestos de trabajo que exijan especiales requisitos profesionales, que serán determinados expresamente por el Consejo Rector. Ahora bien, el legislador limita la duración temporal ampliada de la situación de prueba a un máximo del veinte por ciento del total de socios trabajadores de la cooperativa. No obstante, el apartado 1 del citado precepto ofrece una cierta libertad a las partes, permitiendo su reducción o supresión siempre que exista acuerdo. El acceso es algo más complejo si la persona que pretende adquirir la condición de socia presta servicios por cuenta de la cooperativa en cuestión. El artículo 80.8 de la Ley 27/1999 indica que los estatutos podrán fijar el procedimiento para adquirir el estatus de socio, si bien será preceptiva su conversión si la sociedad cooperativa rebasa el límite de trabajo asalariado establecido en el artículo 80.7 de la Ley 27/1999 y la persona trabajadora formalizó un contrato de trabajo por tiempo indefinido y ostenta una antigüedad superior a dos años. En estos casos, no será necesario superar el periodo de prueba señalado en el artículo 81 de la Ley 27/1999. 
Una vez se ha incorporado a la estructura societaria, la norma ofrece un escenario de estabilidad, toda vez que el vínculo se diseña legalmente para que perviva en el tiempo de forma indefinida. En efecto, la construcción del artículo 13.6 de la Ley 27/1999 establece la posibilidad de admitir socios por un lapso de tiempo determinado, pero para ello será necesario la expresa previsión en los Estatutos y el acuerdo en el momento de la admisión, siempre que el conjunto de estos socios no sea superior a la quinta parte de los socios de carácter indefinido. Por lo tanto, la situación temporal de personas socias en las sociedades cooperativas de trabajo asociado es una circunstancia excepcional.

Si examinamos las opciones que ofrece la Ley 27/1999 con relación a la extinción de la condición de persona socia en este tipo de cooperativas, puede observarse, de igual modo, una apuesta legal por la pervivencia temporal del vínculo societario. Los distintos preceptos que regulan el régimen jurídico de las sociedades cooperativas de trabajo asociado (arts. 80 a 87 de la Ley 27/1999) contemplan la extinción del vínculo por razones de carácter disciplinario conectadas con la prestación de trabajo (art. 82 de la Ley 27/1999) y por causas económicas, técnicas, organizativas o de producción (art. 85 de la Ley 27/1999), que se suman al régimen jurídico general previsto para cualquier sociedad cooperativa en los artículos 17 (baja voluntaria y obligatoria de las personas socias) y 18 (cese disciplinario). Sin ánimo de abordar las similitudes o diferencias entre ambos regímenes (González Del Rey Rodríguez, I., 2008; López Gandía, J., 2006), el planteamiento legal, de nuevo, es coincidente con la idea de pervivencia o mantenimiento de las relaciones que se produzcan en el seno de la sociedad cooperativa de trabajo asociado.

Todo ello permite afirmar que nos encontramos ante un escenario legal que regula mínimamente las condiciones de acceso a las sociedades cooperativas de trabajo asociado, ofreciendo una gran libertad a las sociedades cooperativas para establecer las condiciones de acceso que consideren oportunas. De hecho, las escasas limitaciones al acceso se complementan con un esquema legal que opta por el mantenimiento de las relaciones entre sociedad y persona socia, a través de la pervivencia del vínculo con carácter indefinido y la escasa regulación de supuestos extintivos basados esencialmente en incumplimientos disciplinarios o en razones objetivas. Se aprecia, pues, una cierta alineación con los valores que propugna el paradigma del trabajo decente, que apuesta firmemente por entornos de trabajo que pervivan en el tiempo, y que, en consecuencia, ofrezcan seguridad laboral.

No obstante, existe, en mi opinión, margen de mejora en la implementación de esta dimensión del trabajo decente, particularmente, con relación a la situación de prueba de las personas socias. Como ya se ha examinado, la redacción del artículo 81 de la Ley 27/1999 opta por un marco que limita el tiempo máximo, y, de hecho, exige la inclusión de esta posibilidad en los estatutos y permite su reducción o eliminación por las partes. Sin embargo, el problema no es tanto la duración, sino el incierto estatus jurídico de la persona durante el periodo que se extienda esta situación, que choca con la idea de estabilidad predicada por esta dimensión del trabajo decente. A diferencia del periodo de prueba previsto en el artículo 14 del TRLET, institución con la que tan sólo comparte su finalidad (Montoya Melgar, A., 1980), los derechos y deberes de la persona socia en situación de prueba no son equivalentes a los reconocidos a las personas socias de la cooperativa. A título de ejemplo, el artículo 81 de la Ley 27/1999 no contempla derecho a voto ni responsabilidad económica alguna. Asimismo, el citado precepto de la Ley 27/1999 no regula una situación técnicamente posible en la que la situación de prueba no tendría sentido. Concretamente, me estoy refiriendo a la posibilidad de que una persona trabajadora, que ha prestado servicios para la sociedad cooperativa de trabajo asociado previamente, acceda a la condición de socio/a. Este tipo de sociedades cooperativas pivotan sobre la idea de la prestación de servicios, y esa es precisamente la razón por la que la integración de la persona en la sociedad cooperativa de trabajo asociado no implica un cambio en la forma de prestar servicios, sino en su vínculo jurídico. En consecuencia, la transición a la condición de socio a través de la situación de prueba retrasa la integración de la persona en la sociedad cooperativa y colisiona con la pretensión de estabilidad predicada en esta dimensión del paradigma de trabajo decente.

Ante este escenario, una visión acorde con los objetivos del trabajo decente exigiría, en mi opinión, replantear la duración de la situación de prueba de las personas socias, bien a través de su eliminación bien mediante la reducción de su duración máxima, aproximando los periodos de tiempo del artículo 81 de la Ley 27/1999 a los previstos en el artículo 14 del TRLET. La existencia de una institución como esta en el marco de las sociedades cooperativas de trabajo asociado no aporta las ventajas que el régimen jurídico del periodo de prueba en el marco de cualquier relación laboral, toda vez que el periodo de prueba se diseña como una vía para ensayar la relación laboral, y, sobre todo, para facilitar la finalización del vínculo contractual a la parte más débil como consecuencia de la sumisión de facto de la persona trabajadora a la estructura empresarial. En las sociedades cooperativas, las relaciones de dependencia no son idénticas a las que acontecen en un contexto de laboralidad, y, de hecho, un mecanismo como la situación de prueba de las personas socias es redundante a la luz de la Ley 27/1999. En efecto, la salida de la persona socia en cualquier momento mediante la solicitud de baja voluntaria al amparo del art. 17.1 de la Ley 27/1999 y la baja obligatoria de las personas socias en aquellos supuestos en los que pierdan los requisitos exigidos, bien en la ley bien en los estatutos de la sociedad cooperativas (art. 17.5 de la Ley 27/1999), son claras muestras de mecanismos propios de las sociedades cooperativas que permiten llevar a cabo las funciones características 
del periodo probatorio sin suprimir la equiparación de derechos entre personas socias y personas socias no plenas (Díaz De La Rosa, A., 2008:142, que cita a (Paz Canalejo, N., 1982). Y, en segundo lugar, debería incluirse, asimismo en el marco del artículo 81 de la Ley 27/1999, la imposibilidad de formalizar una situación de prueba en aquellas situaciones en las que la persona en cuestión haya prestado servicios con carácter previo en la sociedad cooperativa de trabajo asociado.

\subsection{La configuración de las condiciones de trabajo y su conexión con las condiciones de libertad en el empleo: jornada, periodos de descanso y permisos retribuidos}

Las condiciones de libertad en el empleo en el marco del paradigma del trabajo decente se concretan en asegurar una elección personal libre de la profesión o el trabajo, y, por lo tanto, implica la erradicación del trabajo en servidumbre, en esclavitud y el trabajo infantil. La contextualización de esta primera idea en el marco de las sociedades cooperativas de trabajo asociado se halla plenamente implementada o superada, toda vez que el concepto legal de sociedad cooperativa parte de la base de la asociación voluntaria de personas en régimen de libre adhesión (art. 1 de la Ley 27/1999).

No obstante, la traslación de este aspecto al escenario laboral de las sociedades cooperativas de trabajo asociado exige un análisis de la regulación normativa de las condiciones de trabajo, a fin de valorar la adecuación de esta a los estándares del trabajo decente. El artículo 83 de la Ley 27/1999 se encarga de establecer una regulación mínima en materia de jornada, descanso semanal, fiestas, vacaciones y permisos para los socios trabajadores, permitiendo una intervención normativa sobre estas cuestiones a los Estatutos, el Reglamento de régimen interno o, en su defecto, a la Asamblea General. En este sentido, el contenido referido en el artículo 83 de la Ley 27/1999 actúa como norma de derecho necesario relativo, y, por lo tanto, su regulación extralegal tan sólo podrá mejorar las cifras plasmadas en la ley. Este esquema también se extiende a los permisos, regulados en el apartado 2 del artículo 83 de la citada ley, de tal manera que las situaciones previstas en la ley que permiten que la persona socia pueda ausentarse previo aviso y justificación, así como su duración, podrán ser ampliadas por los Estatutos, el Reglamento de régimen interno o, en su defecto, la Asamblea General. Sin embargo, el artículo 83 de la Ley 27/1999 presenta deficiencias para garantizar regímenes de trabajo en condiciones de libertad, y, en consecuencia, admite margen de mejora y adecuación a los estándares del trabajo decente. Los puntos más conflictivos del citado precepto son la fijación de la jornada, los descansos y el carácter retribuido de los permisos, que ofrecen una extrema flexibilidad no acorde con el paradigma del trabajo decente.

Respecto al establecimiento de la jornada y los periodos de descanso, las letras a) y b) del artículo 83 de la Ley 27/1999 se encargan de señalar un mínimo de doce horas de descanso entre jornadas diarias y un máximo de cuarenta horas de trabajo a la semana para aquellas personas menores de dieciocho años. Cómo puede observarse, cuestiones como la duración de la jornada ordinaria de trabajo, ya sea semanal o diaria, el número máximo de horas ordinarias de trabajo efectivo o los periodos de descanso en jornadas especialmente largas no se hallan reguladas, y su configuración se remite a lo previsto en los estatutos, el Reglamento de régimen interno o, en su defecto, la Asamblea. Si bien la no regulación en la ley de estas circunstancias que garantizan condiciones de trabajo dignas podría atribuirse a la naturaleza asociativa de las sociedades cooperativas de trabajo asociado, y ello justificaría a priori la diferencia entre el marco regulador de la Ley 27/1999 y el TRLET, la incidencia de tales ausencias es especialmente grave porque dibuja un escenario de ventaja competitiva por la vía de la eliminación de derechos. Sin embargo, la especial gravedad de la desregulación de los mínimos de la prestación de servicios en sociedades cooperativas de trabajo asociado se produce por la falta de encaje con instrumentos internacionales y europeos, que forman parte del ordenamiento jurídico ex artículo 96.1 de la CE. En particular, las disposiciones concretas con las que choca frontalmente la regulación del artículo 83.1 de la Ley 27/1999 son el artículo 2 del Convenio de la OIT núm. 1 sobre las horas de trabajo (1919), que establece una jornada máxima diaria de ocho horas y semanal de cuarenta y ocho horas, y los artículos 4 y 5 de la Directiva 2003/88/CE del Parlamento Europeo y del Consejo, de 4 de noviembre de 2003, relativa a determinados aspectos de la ordenación del tiempo de trabajo, que señalan el disfrute de una pausa de descanso cuando el tiempo de trabajo diario sea superior a seis horas, un período mínimo de descanso ininterrumpido de veinticuatro horas por cada siete días.

Con relación al carácter retribuido de los permisos, el artículo 83.2 in fine de la Ley 27/1999 opta por no pronunciarse explícitamente, pero señala la obligación de que los Estatutos, el Reglamento de régimen interno, o en su defecto, la Asamblea General establezcan obligatoriamente si serán remunerados. Este planteamiento aboga por ofrecer una cierta flexibilidad, pero de nuevo encuentra dificultades de compatibilidad con instrumentos internacionales ratificados por España, no tanto por el carácter retribuido de los permisos, sino por la omisión de una licencia incluida en un Convenio de la OIT ratificado por España. Concretamente, el Convenio de la OIT núm. 140 sobre la licencia pagada de estudios (1974) contempla en su artículo 2 una licencia, con fines educativos y a desarrollar durante las horas de trabajo, que lleva aparejada el pago de prestaciones económicas adecuadas. Si bien la ausencia explícita de este permiso en el marco del artículo 83.2 de la Ley 27/1999 podría solventarse por la vía de la ampliación prevista en el último párrafo 
del citado precepto, el verdadero conflicto con la norma internacional se origina por la libertad, legitimada por la norma española, de acordar su carácter no retribuido. Todo ello, sin perjuicio de que la facultad de acordar o no el carácter retribuido de los permisos del artículo 83 de la Ley 27/1999 puede dar lugar a situaciones en las que se fomente la no utilización o renuncia colectiva pactada de este derecho de las personas socias trabajadoras. Y esta última circunstancia es especialmente importante porque los supuestos de permisos previstos en la Ley 27/1999 están conectados con circunstancias personales, que suponen la obstaculización para una efectiva conciliación de la vida laboral y familiar.

Ante este escenario, la adecuación del artículo 83 de la Ley 27/1999 al paradigma del trabajo decente exigiría reformular tanto el apartado 1 como el apartado 2. En este sentido, sería recomendable incluir las limitaciones relativas a la jornada diaria y semanal apuntadas anteriormente, la obligatoriedad de realizar pausas de descanso en jornadas de trabajo superiores a seis horas, y, por último, la previsión de un derecho a un permiso retribuido por estudios.

\subsection{La igualdad de oportunidades como reto pendiente para lograr el trabajo decente en las sociedades cooperativas de trabajo asociado}

El paradigma del trabajo decente presta una especial atención a la incorporación de una dimensión integradora en el empleo. El objetivo 8.5 de la Resolución núm. 70/1 insiste en lograr el empleo pleno y productivo y la igualdad de remuneración, introduciendo la necesaria participación de mujeres, jóvenes y personas con discapacidad. Las razones que justifican el fomento específico de los citados colectivos se basan en la especial vulnerabilidad a la inseguridad laboral, y concretamente, a la mayor presencia de aquellos en la prestación de servicios a tiempo parcial con contratos temporales, y por consiguiente, con una remuneración más baja.

El objetivo de reforzar la igualdad de oportunidades dentro de este paradigma, que también ha sido apuntado en sede europea por el apartado I.9 de la Res. de 4 de julio de 2017, tiene implicaciones jurídicas muy importantes en el ámbito normativo. Concretamente, exige instrumentar elementos normativos que faciliten la incorporación de tales colectivos, circunstancia esta que puede colegirse de la simple lectura del objetivo de desarrollo sostenible. Sin embargo, también se extiende al mantenimiento y obstaculización de la expulsión del mercado de trabajo de estos colectivos. Y ello implica, "[...] gozar de un trato justo y equitativo y de oportunidades profesionales del mismo signo" y "[...] la ausencia de discriminación en la contratación y en el trabajo y la posibilidad de conciliar de modo equilibrado la actividad laboral con la vida familiar" (Anker, R. Et Al., 2003:166). Es por ello, pues, que puede colegirse, además de la integración de las mujeres, jóvenes y personas con discapacidad, la prohibición de discriminación por razón de género, edad y discapacidad y la previsión de mecanismos de conciliación de la vida laboral y familiar del citado objetivo de desarrollo sostenible.

Ante este escenario, ¿qué cuestiones deberían ser modificadas o incorporadas en el marco de la Ley 27/1999? Ciertamente, la igualdad de oportunidades es una asignatura pendiente en el marco regulador, tanto de las sociedades cooperativas en general como, en particular, de aquellas de trabajo asociado. En efecto, la citada norma no incluye ningún precepto que aborde esta dimensión del trabajo decente, y sería recomendable efectuar distintas modificaciones e incorporaciones, ya no sólo para incluir una visión que fomente la igualdad de oportunidades de los tres colectivos mencionados anteriormente, sino para ofrecer un marco de protección acorde con las previsiones del resto de normas existentes en nuestro ordenamiento jurídico, a saber la Ley Orgánica 3/2007, de 22 de marzo, para la igualdad efectiva de mujeres y hombres y el Real Decreto Legislativo 1/2013, de 29 de noviembre, por el que se aprueba el Texto Refundido de la Ley General de derechos de las personas con discapacidad y de su inclusión social.

Como primera propuesta, los criterios de admisión de nuevos socios deberían respetar la igualdad de oportunidades, que debería ser una exigencia legal con carácter general. La regulación actual traslada a los estatutos la previsión de qué criterios se tomarán en cuenta para la incorporación de nuevas personas, pero el marco regulador sólo exige que aseguren la equitativa y ponderada participación de estos socios en las obligaciones y derechos de naturaleza social y económica (Art. 13.4 de la Ley 27/1999). De hecho, la falta de control de legalidad sobre los criterios de admisión se extiende incluso en sede registral, toda vez que la inscripción de los estatutos en el Registro de Sociedades Cooperativas se limita a un control de legalidad formal, y en ningún caso sustantivo, tal y cómo puede colegirse del artículo 109 de la Ley 27/1999 y de los artículos 7.2, 15 y 19 del Real Decreto 136/2002, de 1 de febrero, por el que se aprueba el Reglamento del Registro de Sociedades Cooperativas.

El control de los criterios de admisión es relevante ya no sólo a efectos de incorporar a la persona en la sociedad cooperativa, sino también para evitar que la existencia de factores relacionados con la persona y protegidos por el marco regulador antidiscriminatorio puedan suponer la baja obligatoria por la pérdida de requisitos ex artículo 17.5 de la Ley 27/1999. En este punto, algunos sectores de la doctrina han defendido que el artículo 27.2 de la Ley 62/2003, de 30 de diciembre, de medidas fiscales, administrativas y del orden social (en adelante, Ley 62/2003), que transpone a nuestro ordenamiento jurídico las Directivas 2000/43/CE 
y 2000/78/CE, solventa de facto el silencio de la Ley 27/1999, toda vez que su ámbito de aplicación material se extiende a todas las personas, tanto en el sector público como en el sector privado, y por lo tanto, "[...] debe entenderse aplicable también a los socios trabajadores de cooperativas de trabajo asociado [....]" (López Gandía, J., 2006:163).

Técnicamente no hay nada que objetar a la aplicación del citado artículo 27.2 de la Ley 62/2003 en el ámbito de las sociedades cooperativas de trabajo asociado, pero la dispersión normativa derivada de la inclusión en una norma que regula multitud de cuestiones supone, en mi opinión, que pase desapercibida para los operadores jurídicos, y especialmente para aquellas personas que ostenten una o varias circunstancias protegidas. Así, este planteamiento no ofrece garantías suficientes de no discriminación en la admisión de personas socias, y debería ser modificado. A título de sugerencia, una solución interesante sería recuperar parcialmente el contenido del artículo 31.1 de la Ley 3/1987, de 2 de abril, General de Cooperativas. Tal precepto limitaba la libertad de los estatutos para fijar los criterios de admisión mediante una cláusula que prohibía su conexión con motivos políticos, sindicales, religiosos, de nacionalidad, sexo, raza o estado civil. No obstante, convendría añadir a estos las causas previstas en el citado artículo 27.2 de la Ley 62/2003 y no contempladas en la norma de 1987, que son la discapacidad, la edad y la orientación sexual.

En segundo lugar, la Ley 27/1999 debería contemplar una expresa prohibición de toma de decisiones en el seno cooperativo que puedan generar discriminación basada en una o varias de las circunstancias apuntadas anteriormente. La redacción actual de la norma no contiene ninguna previsión al respecto, y permite, de facto, que órganos sociales como la Asamblea General y el Consejo Rector puedan adoptar decisiones justificadas en el sexo, la discapacidad o la edad, por citar algunas. Esta cuestión es, en mi opinión, especialmente trascedente en el seno de la Asamblea General, toda vez que es el órgano social encargado de fijar la política social de la sociedad cooperativa (art. 21 de la Ley 27/1999) y de modificar tanto los Estatutos como el Reglamento de régimen interno de la cooperativa (Art. 21.2.c de la Ley 27/1999). Como puede observarse, el actual escenario no ofrece ningún tipo de garantía o control de que la toma de decisiones en el seno de la sociedad cooperativa no será discriminatoria o atentará contra la igualdad de oportunidades, y ello colisiona frontalmente con el paradigma de trabajo decente. La norma podría solucionar esta cuestión a través de la incorporación de una cláusula de protección antidiscriminatoria en la toma de decisiones del seno de la sociedad cooperativa en el marco del artículo 21 de la Ley 27/1999. Dicha disposición debería incluir tanto las distintas circunstancias prohibidas cómo la definición y prohibición expresa de distintos tipos de discriminación (directa e indirecta), en términos similares a los contemplados en el artículo 2 de la Directiva 2000/78. Además, sería interesante ampliar la tipología de modalidades de protección mediante la incorporación de categorías más recientes, como son la discriminación múltiple o por asociación, que actualmente no se hallan previstas de forma expresa en la citada norma europea pero sí que pueden encontrarse en normas vigentes del ordenamiento jurídico español (Real Decreto Legislativo 1/2013).

Por último, una perspectiva legal que asuma una visión acorde con la igualdad de oportunidades en el marco del paradigma del trabajo decente exigiría el incremento de mecanismos de conciliación de la vida laboral y familiar. En la actualidad, la Ley 27/1999 contempla algunas medidas en el marco de las sociedades cooperativas, y en particular, de trabajo asociado. Concretamente, se incluyen el derecho a ausentarse del trabajo por motivo del nacimiento de hijo o por el fallecimiento, accidente o enfermedad graves u hospitalización de parientes hasta el segundo grado (art. 83.2.b de la Ley 27/1999) y la suspensión de la obligación y el derecho de la persona socia trabajadora a prestar su trabajo, con pérdida de los derechos y obligaciones económicas de dicha prestación, por maternidad, paternidad y adopción o acogimiento de menores de cinco años (art. 84.1.b de la Ley 27/1999). Si bien sólo estas dos situaciones se hallan cubiertas específicamente por la Ley 27/1999, se contempló, con posterioridad a la citada norma, la aplicación de mecanismos de conciliación de la vida familiar y laboral en el ámbito de las sociedades cooperativas en la Ley 39/1999, de 5 de noviembre, para promover la conciliación de la vida familiar y laboral de las personas trabajadoras. A través de su disposición adicional primera, se permite que las personas socias de sociedades cooperativas puedan acogerse a los beneficios establecidos en la citada norma durante los períodos de descanso por maternidad (Arts. 3 y 10), riesgo durante el embarazo (Arts. 3, 6, 14 y 21) adopción y acogimiento (arts. 3 y 18). De forma más concreta, las personas socias pueden acceder a la suspensión de la prestación de servicios y los derechos económicos derivados en situaciones de riesgo durante el embarazo (art. 3 de la Ley 39/1999), reducción del número de horas de prestación de servicios por lactancia de un hijo menor de nueve meses y cuidado directo algún menor de seis años o un minusválido físico, psíquico o sensorial, que no desempeñe una actividad retribuida cuidado directo de un familiar, hasta el segundo grado de consanguinidad o afinidad, que por razones de edad, accidente o enfermedad no pueda valerse por sí mismo, y que no desempeñe actividad retribuida (Art. 2 de la Ley 39/1999) y la solicitud de excedencias por cuidado de hijos/as y/o familiares (Art. 4 de la Ley 39/1999).

La diversa tipología legal de sociedades cooperativas podría justificar, en un primer momento, la dispersión normativa, diseñando un marco de mínimos sobre este tipo de medidas en la Ley 27/1999, toda vez que cooperativas como por ejemplo de consumidores y usuarios o de viviendas no requieren la 
instrumentación de este tipo de cuestiones. Ahora bien, la configuración de mecanismos de conciliación de la vida laboral y familiar es un asunto de vital importancia en cualquier actividad productiva que se desarrolle, y en especial, en las sociedades cooperativas de trabajo asociado. Como ya se ha apuntado, este tipo de actividades cooperativizadas implica la creación de puestos de trabajo, y, por lo tanto, existe la necesidad de proveer garantías para favorecer que las personas socias, pese a ostentar un vínculo societario, puedan compatibilizar la prestación de servicios sin alterar su vida personal. Y en este punto, la aplicación de mecanismos previstos en dos normas distintas resulta poco eficaz para garantizar la aplicación efectiva de las citadas garantías para compatibilizar la vida profesional, personal y familiar de las personas socias.

Sin ánimo de entrar en los problemas interpretativos que plantea la aplicación de la Ley 39/1999, sí que es conveniente indicar que su ámbito objetivo de aplicación está planteado para situaciones que acontezcan en el marco del trabajo por cuenta ajena. Y esta circunstancia implica que la remisión efectuada en la disposición adicional primera de la Ley 39/1999 dificulta la pretendida ampliación normativa en el ámbito de las sociedades cooperativas de trabajo asociado. La previsión de la aplicación de distintas medidas a través de una disposición adicional en la Ley 39/1999, sin que la norma reguladora de las sociedades cooperativas reproduzca su contenido, con las debidas adaptaciones a las particularidades propias de este tipo de sociedades, tiene graves consecuencias negativas para aproximar el marco regulador a esta dimensión del paradigma del trabajo digno. Todo ello, sin perjuicio de que la dispersión de los mecanismos en dos normas puede generar una cierta desinformación de los derechos que en esta materia disponen las personas socias.

A modo de propuesta, sería recomendable que la Ley 27/1999 incluyera un artículo específico dedicado a la conciliación de la vida laboral y familiar en las sociedades cooperativas de trabajo asociado, integrando los distintos mecanismos incluidos en la Ley 39/1999 y adaptados jurídicamente a las particularidades de desarrollo de la actividad productiva de este tipo de sociedades cooperativas. Así, por ejemplo, el legislador podría optar por incluir una lista cerrada de medidas de conciliación, o bien podría constatar la necesidad de que los estatutos se pronuncien sobre la existencia de mecanismos de conciliación y las condiciones para su ejercicio por las personas socias.

\section{Conclusiones}

El paradigma del trabajo decente aparece como un planteamiento jurídico que pretende garantizar empleos de calidad, salvaguardar y respetar los derechos de las personas trabajadoras y asumir una igualdad de oportunidades real entre hombres y mujeres, todo ello sin sacrificar competitividad en estructuras productivas. Este modelo, cuya apuesta institucional se ha mantenido constante tanto en el ámbito internacional como europeo, introduce, como ya se ha apuntado, un elemento cualitativo que se identifica como un nuevo estándar para garantizar empleos de calidad. Su encaje en el marco de las sociedades cooperativas de trabajo asociado, que parten de un régimen democrático de participación en la vida económica y pretenden la creación y mantenimiento de empleo estable para los socios, es ideal, toda vez que en este tipo de sociedades existe coincidencia de las figuras de empresario/a y persona trabajadora.

Desde una óptica jurídica, las conexiones entre empleo y sociedades cooperativas de trabajo asociado se evidencian desde distintos ámbitos. En primer lugar, desde una perspectiva constitucional, a través de la formulación e interpretación de los artículos 129.2, 35, 38 y 40 CE, todo ello pese a las limitaciones derivadas del reparto competencial entre el Estado y las Comunidades Autónomas. Pero también se aprecia desde el ámbito legal, en el marco de los artículos 80 a 87 de la Ley 27/1999, y específicamente a tenor del objetivo de las sociedades cooperativas de trabajo asociado, que no es otro que proporcionar puestos de trabajo a sus socios (art. 80). En líneas generales, el legislador ha configurado un marco jurídico que apuesta por integrar de manera equilibrada un marco jurídico tuitivo, manifestado en la previsión de algunas normas de carácter legal de derecho mínimo necesario y no disponibles por los estatutos, el reglamento de régimen interno o la Asamblea General. En este punto, es cierto que el artículo 81 de la Ley 27/1999 indica que la relación entre las personas socias y la sociedad cooperativa será societaria, circunstancia esta que podría considerarse un primer obstáculo para la implementación del trabajo decente. Sin embargo, la naturaleza de la prestación de servicios en este tipo de sociedades cooperativas es muy próxima a la desarrollada en las relaciones laborales, ya no sólo por el acercamiento normativo de la Ley 27/1999 al TRLET al establecer un marco jurídico de mínimos en cuestiones como el descanso semanal, las fiestas, vacaciones, permisos, jornada (art. 83), suspensiones, excedencias (art. 84) o régimen disciplinario (art. 82), sino porque la competencia jurisdiccional para conocer las cuestiones litigiosas derivadas de la prestación de servicios corresponde a la jurisdicción social en la actualidad (art. 2.c de la LRJS), y ello es así desde la Ley 3/1987. Sin embargo, donde se aprecia una mayor notoriedad ha sido en el ámbito judicial, que ha experimentado un acercamiento de la finalidad tuitiva propia del Derecho del Trabajo en las relaciones entre sociedad cooperativa y personas socias trabajadoras. La aplicación de la doctrina judicial del levantamiento del velo en situaciones de utilización fraudulenta de sociedades cooperativas de trabajo asociado (Sentencia del Tribunal Supremo núm. 549/2018. de 18 de mayo - Rec. 3513/2016), el encuadramiento de las personas 
socias de sociedades cooperativas de trabajo asociado en el Régimen General de Seguridad Social y el acceso a la protección social que ofrece el sistema de Seguridad Social (Sentencias del Tribunal Supremo de 20 de noviembre de 2018, 19 de diciembre de 2018 y 7 de febrero de 2019 - Recs. 3407/2016, 2233/2017 y 649/2017) o el reconocimiento de la existencia y ejercicio de derechos de participación colectiva (libertad sindical - art. $28 \mathrm{CE}$ ) a los socios trabajadores de sociedades cooperativas de trabajo asociado (Sentencia del Tribunal Supremo núm. 347/2019 de 8 de mayo - Rec. 42/2018) son ejemplos evidentes de la creciente conexión señalada anteriormente. En consecuencia, las citadas aproximaciones jurídicas, tanto desde un punto de vista normativo como judicial, permiten afirmar la posibilidad de formular propuestas viables de implementación normativa del trabajo decente en sociedades cooperativas de trabajo decente. De hecho, la actualización normativa de la Ley 27/1999 no es sólo necesaria a efectos de implementar distintos aspectos del paradigma de trabajo decente, sino que es conveniente a la luz de nuevos fenómenos de organización empresarial, principalmente derivados de la economía colaborativa, que han surgido a lo largo de los últimos años.

De forma más concreta, las propuestas de adaptación de la norma que se han sugerido en esta contribución parten de conjugar cuatro dimensiones del paradigma del trabajo decente con necesidades de actualización o incorporación del marco regulador de las sociedades cooperativas de trabajo asociado. Así, los aspectos o preceptos que requieren una intervención jurídica más inmediata son:

a) Los anticipos societarios (art. 80.4 de la Ley 27/1999), que se conectan con el carácter productivo de la prestación de servicios y la necesidad de garantizar un medio de subsistencia aceptable para las personas socias. La configuración actual asegura una percepción en el tiempo, pero no se pronuncia a propósito de un valor mínimo de su cuantía, que puede ser un factor que agrave la posible utilización fraudulenta de las sociedades cooperativas de trabajo asociado por razones competitivas. La propuesta de modificación que se propone parte de reconocer una cuantía mínima tomando como modelo el importe, en cómputo anual, del salario mínimo interprofesional, recuperando así la regla prevista en el artículo 48.5 de la Ley 52/1974, de 19 de diciembre, General de Cooperativas, que podría ser complementado con una sugerencia ya apuntada previamente por la doctrina, a saber, la obligación de tomar como referencia mínima las tablas salariales contenidas en el convenio colectivo aplicable a la actividad económica cooperativizada.

b) La situación de prueba de las personas socias (art. 81 de la Ley 27/1999), vinculada con la necesidad de ofrecer oportunidades de empleo estable. En líneas generales, nos encontramos ante un escenario legal que regula mínimamente las condiciones de acceso a las sociedades cooperativas de trabajo asociado. De hecho, la ausencia de limitaciones al acceso se complementa con un esquema legal que opta por el mantenimiento de las relaciones entre sociedad y persona socia, a través de la pervivencia del vínculo con carácter indefinido y la escasa regulación de supuestos extintivos, basados esencialmente en incumplimientos disciplinarios o en razones objetivas. Sin embargo, existe margen de mejora con relación al incierto estatus jurídico de la persona durante el periodo que se extienda esta situación. En mi opinión, una visión acorde con los objetivos del trabajo decente exigiría modificar la duración de la situación de prueba de las personas socias, bien a través de su eliminación bien mediante la reducción de su duración máxima, aproximando los periodos de tiempo del artículo 81 Ley 27/1999 a los previstos en el artículo 14 TRLET

c) La configuración de las condiciones de trabajo (art. 83 de la Ley 27/1999), como base para garantizar condiciones de libertad en el empleo. La configuración legal de las condiciones de trabajo presenta opciones de mejora, especialmente con relación a la jornada, los periodos de descanso y los permisos retribuidos. Respecto al establecimiento de la jornada y los periodos de descanso, la duración de la jornada ordinaria de trabajo, ya sea semanal o diaria, el número máximo de horas ordinarias de trabajo efectivo y los periodos de descanso en jornadas especialmente largas no se hallan reguladas, y, por lo tanto, se aprecia una falta de encaje con instrumentos internacionales y europeos que regulan precisamente tales aspectos, y que forman parte del ordenamiento jurídico ex artículo 96.1 de la CE. La adecuación de la Ley 27/1999 exigiría introducir, en el marco de su artículo 83.1, limitaciones relativas a la jornada diaria y semanal y la obligatoriedad de realizar pausas de descanso en jornadas de trabajo superiores a seis horas. En cuanto al régimen de permisos, la necesidad de modificar el artículo 83.2 de la Ley 27/1999 no gira tanto en torno a la exigencia legal de implementar el carácter retribuido, facultad reservada a los Estatutos, el Reglamento de régimen interno, o en su defecto, la Asamblea General, sino a la necesaria incorporación de una licencia, con fines educativos y a desarrollar durante las horas de trabajo como consecuencia de la ratificación por España del Convenio de la OIT núm. 140 sobre la licencia pagada de estudios (1974).

d) La implementación de mecanismos de igualdad de oportunidades entre hombres y mujeres. Esta dimensión del paradigma de trabajo decente es, con diferencia, la que requiere un mayor 
esfuerzo del legislador. En la actualidad, la Ley 27/1999 no contiene referencias sobre esta cuestión, y sería recomendable efectuar distintas modificaciones e incorporaciones, ya no sólo para incluir una visión que fomente la igualdad de oportunidades entre hombres y mujeres y respecto a otros colectivos (jóvenes y personas con discapacidad), sino para ofrecer un marco de protección acorde con otras normas del ordenamiento jurídico español. De forma concreta, convendría introducir reglas en el marco del artículo 13 de la Ley 27/1999, relativas a los criterios de admisión de nuevas personas socias, que prohíban establecer circunstancias relacionadas con el sexo, la edad, la discapacidad, la raza o la orientación sexual, entre otras. A este mecanismo debería añadirse una expresa prohibición, esta vez en el artículo 21 de la Ley 27/1999, de toma de decisiones en el seno cooperativo que puedan generar situaciones de discriminación basadas en una o varias de las circunstancias apuntadas anteriormente. Y, por último, sería conveniente incorporar un precepto en el marco de la Ley 27/1999 dedicado a la conciliación de la vida laboral y familiar en las sociedades cooperativas de trabajo asociado. Su contenido implicaría incluir una lista cerrada de medidas de conciliación, o bien constatar la necesidad de que los estatutos se pronuncien sobre la existencia de mecanismos de conciliación y las condiciones para su ejercicio por las personas socias.

\section{Referencias bibliográficas}

Alfonso Sánchez, R. (2009) La legislación española sobre cooperativas y sociedades laborales: ¿Una respuesta adecuada a las necesidades del sector?, CIRIEC - España. Revista Jurídica de Economía Social y Cooperativa, $\mathrm{N}^{\circ}$ 20, pp. 9-42.

Alfonso Sánchez, R. (2016) Economía colaborativa: un nuevo mercado para la economía social, CIRIEC - España. Revista de Economía Pública, Social y Cooperativa, No 88, pp. 231-258.

Alonso Rodrigo, E. (1999) Novedades aportadas por la Ley General de Cooperativas, Anuario de Estudios Cooperativos, $\mathrm{N}^{\circ} 1$, pp. 133-156.

Alonso Soto, F. (1984) Las relaciones laborales en las cooperativas en España, Revista Española de Derecho del Trabajo, $\mathrm{N}^{\circ} 20$, pp. 525-560.

Anker, R., Chernyshev, I., Egger, P., Mehran, F., y Ritter, J. (2003) La medición del trabajo decente con indicadores estadísticos, Revista Internacional del Trabajo, Vol. 122 No 2, pp. 161-195.

Arrieta Idiakez, F.J. (2019) Las cooperativas digitales como cauce para el trabajo digital en el contexto de la economía colaborativa, Revista de Derecho Social, $\mathrm{N}^{\circ} 85$, pp. 233-250.

Arroyo Sánchez, P. (2003) La Constitución Española y las Cooperativas de Trabajo Asociado, CIRIEC - España. Revista de Economía Pública, Social y Cooperativa, Vol. 47, pp. 69-78.

Bescond, D., Châtaignier, A., y Mehran, F. (2003) Siete indicadores para medir el trabajo decente. Comparación internacional, Revista Internacional del Trabajo, Vol. $122 \mathrm{~N}^{\circ}$ 2, pp. 197-231.

Blanco Morales, J. (2000) Aspectos destacados de la Ley Estatal de Cooperativas 27-1999, de 16 de julio, Revista universitaria de ciencias del trabajo, $\mathrm{N}^{\circ} 1$, pp. 153-168.

Cabeza Pereiro, J. (2014) Cooperativismo, sindicalismo y participación de los trabajadores de la economía social, Revista General de Derecho del Trabajo y de la Seguridad Social, Vol. 37, pp. 88-104.

Calvo Ortega, R. (2003) Las figuras de la economía social en la constitución española de 1978, CIRIEC - España. Revista de Economía Pública, Social y Cooperativa, No 47, pp. 159-174.

Canalda Criado, S. (2019) El fomento del empleo decente y sostenible en cooperativas y sociedades laborales, REVESCO. Revista de Estudios Cooperativos, Tercer Cuatrimestre, $\mathrm{N}^{\circ}$ 132, pp. 77-96.

Cuevas Gallegos, J. (2011) Las Cooperativas de Trabajo Asociado: Otra forma de creación de empleo, Granada: Comares.

Díaz De La Rosa, A. (2008) Sociedad cooperativa, prestación de trabajo y condición de socio, Santiago de Compostela: CECOOP (Centro de estudios cooperativos de la USC).

Díaz De La Rosa, A. (2010) Reflexiones a propósito del artículo 129. 2 de la Constitución Española, Anuario da facultade de dereito da universidade da Coruña, $\mathrm{N}^{\circ} 14$, pp. 311-324.

Escribano Gutiérrez, J. (2010) Cooperativas de trabajo asociado y derechos laborales colectivos de los socioscooperativistas, Revista de Derecho Social, No 49, pp. 97-124.

Espín Sáez, M. (2009) El socio trabajador. Criterios para sistematizar la realidad del autoempleo colectivo, Madrid: CES.

Figueiredo, J., Bonnet, F., y Standing, G. (2003) Una familia de índices de trabajo decente, Revista internacional del trabajo, Vol. 122, $\mathrm{N}^{\circ}$ 2, pp. 233-261.

García Jiménez, M. (2010) La necesaria armonización internacional del Derecho Cooperativo, REVESCO. Revista de Estudios Cooperativos, Segundo Cuatrimestre, $\mathrm{N}^{\circ} 102$, pp. 79-108.

García Jiménez, M. (2015) El marco jurídico aplicable a los socios trabajadores de las cooperativas de trabajo asociado en España. Problemática y propuesta para su mejora. En: Fajardo García, G. (Coord.), Empresas gestionadas por sus trabajadores. Problemática jurídica y social, Valencia: CIRIEC, pp. 187-192.

García-Gutiérrez Fernández, C. (1998) La necesidad de la consideración de la sociedad cooperativa como entidad mercantil para la adecuada regulación, REVESCO. Revista de Estudios Cooperativos, № 66, pp. 207-234. 
García-Gutiérrez Fernández, C. (2001) La sociedad cooperativa como fin y no como instrumento. En: Moyano Fuentes, J. (Dir.), La Sociedad Cooperativa: Un análisis de sus características societarias y empresariales, Jaen: Universidad de Jaén, pp. 281-300.

Ghain, D. (2003) Trabajo decente. Concepto e indicadores, Revista internacional del trabajo, No 122, pp. $125-160$.

González del Rey Rodríguez, I. (2008), El Trabajo Asociado: Cooperativas y Otras Sociedades de Trabajo, Navarra: Aranzadi.

Hierro, F.J. (2003) Las relaciones laborales en las cooperativas de trabajo asociado, Aranzadi Social: Revista Doctrinal, $\mathrm{N}^{\circ} 5$, pp. 1459-1478.

López Gandía, J. (2006) Las cooperativas de trabajo asociado y la aplicación del Derecho del Trabajo, Valencia: Tirant lo Blanch.

Lozano Lares, F. y Salas Porras, M. (2017) Trabajo decente para un futuro sin trabajo, Futuro del trabajo: trabajo decente para todos, Vol. 3, pp. 1-11 (versión electrónica).

Luján Alcaráz, J. (1999) El socio trabajador de las cooperativas de trabajo asociado en la Ley 27/1999, de 16 de julio de cooperativas, Aranzadi Social: Revista Doctrinal, No 5, pp. 127-140.

Marín López, J. (1999) Notas sobre la Ley 27/1999 de 16 de julio, de Cooperativas, La Ley: Revista Jurídica Española de Doctrina, Jurisprudencia y Bibliografía, № 6, pp. 1797-1803.

Merlié, D. y Paoli, P. (2000) Third European Survey on Working Conditions, Luxemburgo: Oficina de Publicaciones Oficiales de la Unión Europea.

Molina Navarrete, C. (2014) Las cooperativas como forma alternativa de creación de puestos de trabajo: El empleo cooperativo entre mitos y realidades, Revista general de derecho del trabajo y de la seguridad social, $\mathrm{N}^{\mathrm{o}} 37$, pp. 5587.

Monereo Pérez, J.L. (2014) La configuración técnica de la relación laboral del socio trabajador de cooperativas de trabajo asociado, Revista general de derecho del trabajo y de la seguridad social, № 37, pp. 14-27.

Montoya Melgar, A. (1980) Sobre el socio-trabajador de la cooperativa de trabajo asociado. En: V.V.A.A. Estudios de Derecho del Trabajo en memoria del profesor Gaspar Bayón Chacón, Madrid: Tecnos, pp. 139-154.

Nogueira Guastavino, M. (2018) Artículo 129: La participación de los interesados en la Seguridad Social y en la empresa. En: Pérez Tremps, P. y Saiz Arnaiz, A. (Dirs.), Comentario a la Constitución Española: 40 Aniversario 1978-2018: Libro-Homenaje a Luis López Guerra, Valencia: Tirant Lo Blanch.

Ortiz Lallana, M.C. (1989) La prestación laboral de los socios en las cooperativas de trabajo asociado, Barcelona: Bosch.

Pastor Sempere, C. (1999a) Notas en torno a las principales novedades de la nueva Ley 27/1999, de 16 de julio, de cooperativas, REVESCO. Revista de Estudios Cooperativos, № 69, pp. 151-182.

Pastor Sempere, C. (1999b) Principales novedades de la nueva Ley 27/1999, de 16 de julio, de Sociedades de Cooperativas, Revista de Derecho de Sociedades, No 13, pp. 229-247.

Paz Canalejo, N. (1980) La Constitución y las Cooperativas, Documentación Administrativa, Nº 186, pp. $76-84$.

Paz Canalejo, N. (1982) La cooperativa como superación del esquema clásico de las relaciones laborales: los socios de trabajo y las cooperativas de producción ante la reforma legislativa, Revista de Política Social, No 133, pp. 7-78.

Paz Canalejo, N. (1999) Perspectivas y problemas jurídicos de la nueva Ley estatal de Cooperativas, REVESCO. Revista de Estudios Cooperativos, № 69, pp. 183-198.

Pedrajas Pérez, F. y Prados de Reyes, F.J. (1975) Notas sobre la caracterización jurídico-laboral de los servicios prestados por el socio-empleado, Revista de Trabajo, N 52, pp. 193-215.

Rodríguez Santos, E. (2018) El régimen retributivo de las personas socias en las sociedades cooperativas de trabajo: una revisión crítica de los modelos normativos, Temas Laborales: Revista Andaluza de Trabajo y Bienestar Social, Vol. 144 , pp. 53-87.

Rojo Torrecilla, E. y Camas Roda, F. (2003) Comentario del artículo 129.2 de la Constitución Española de 1978 y su desarrollo (con especial atención a la participación en la empresa). En: Sempere Navarro, A.V. (Dir.), El Modelo Social En La Constitución Española de 1978, Madrid: Ministerio de Trabajo y Asuntos Sociales, pp. 1467-1503.

Sagardoy Bengoechea, J. A. (1964) Un régimen especial de Seguridad Social: el de los socios trabajadores de cooperativas de producción, Revista de Política Social, Nº 61, pp. 369-393.

Santiago Redondo, K. (1998) Socio de Cooperativa y Relación Laboral, Madrid: Ibidem.

Santiago Redondo, K. (1999) Algunos viejos debates sobre el trabajo asociado tras una primera lectura laboral de la nueva ley general de cooperativas. En: Dueñas Herrero, L. J., I Congreso de Castilla y León sobre relaciones laborales, Valladolid: Lex Nova, pp. 247-268.

Santiago Redondo, K. (2018) Artículo 129.2: La participación en la empresa y el fomento del cooperativismo. En: Sempere Navarro, A. V., Comentarios a la Constitución Española: XXX Aniversario, Vol. 2, Tomo II, Madrid: Wolters Kluwers, pp. 1990-1994.

Spear, R. (2004) El gobierno democrático en las organizaciones cooperativas, CIRIEC - España. Revista de Economía Pública, Social y Cooperativa, No 48 , pp. 11-30.

Uriarte, R. (2004) El mandato constitucional de participación de los trabajadores y la afectación de los derechos de propiedad y libre empresa, Oñati: Instituto Vasco de Administración Pública.

Valdés Dal-Re, F. (1975) Las cooperativas de producción, Madrid: Editorial Montecorvo.

Valdés Dal-Re, F. (1980) Notas sobre el nuevo régimen jurídico de las cooperativas de trabajo asociado, Civitas. Revista Española de Derecho Del Trabajo, Vol. 1, pp. 71-94.

Valdés Dal-Re, F. (2010) La cooperativa de trabajo asociado: una mirada desde las legislaciones estatal y autonómica, Relaciones Laborales, Vol. 2, pp. 67-78.

Vergéz Sánchez, M., (1973) El derecho de las cooperativas y su reforma, Madrid: Civitas. 
Vicent Chuliá, F. (1979) El accidentado desarrollo de nuestra legislación cooperativa, Revista Jurídica de Cataluña, Vol. $78 \mathrm{~N}^{\mathrm{o}} 4$, pp. 869-906.

Vicent Chuliá, F. (2002) El tercer sector: las sociedades cooperativas y otras formas de economía social. En: Aparicio Tovar, J., Comentario a la Constitución Socio-Económica de España, Granada: Comares, pp. 719-732.

Vida Soria, J. y Prados de Reyes, F.J. (1998) Artículo 129: Principios constitucionales sobre la participación social: aplicación y desarrollo. En: Alzaga, O., Comentarios a la Constitución Española de 1978 (Tomo X), Madrid: EDERSA, pp. 88-119.

Vila Tierno, F. (2014) Algunas notas en relación a la prestación de trabajo en las cooperativas. Una especial atención a las formas de extinción, Revista General de Derecho Del Trabajo y de La Seguridad Social, No 37, pp. 136-160.

\section{Referencias legales}

Convenio de la OIT núm. 1 sobre las horas de trabajo. Accesible en: https://www.ilo.org/dyn/normlex/es/f?p=NORMLEXPUB:12100:0::NO::P12100_ILO_CODE:C001.

Convenio de la OIT núm. 98 sobre el derecho de sindicación y de negociación colectiva. Accesible en: https://www.ilo.org/dyn/normlex/es/f?p=NORMLEXPUB:12100:0::NO::P12100_ILO_CODE:C098.

Convenio de la OIT núm. 140 sobre la licencia pagada de estudios. Accesible en: https://www.ilo.org/dyn/normlex/es/f?p=NORMLEXPUB:12100:0::NO::P12100_ILO_CODE:C140.

Recomendación núm. 127 de la OIT sobre las cooperativas. Accesible en: https://www.ilo.org/dyn/normlex/es/f?p=NORMLEXPUB:12100:::NO:12100:P12100_ILO_CODE:R127:NO.

Recomendación núm. 193 de la OIT sobre la promoción de las cooperativas. Accesible en: https://www.ilo.org/dyn/normlex/es/f?p=NORMLEXPUB:12100:0::NO::P12100_ILO_code:R193.

Memoria del Director General presentada en la $87^{\text {a }}$ reunión de la Conferencia Internacional del Trabajo "Trabajo decente" (junio de 1999, ISBN 92-2-310804-7). Accesible en: https://www.ilo.org/public/spanish/standards/relm/ilc/ilc87/rep-i.htm.

Resolución núm. 70/1 de la Asamblea General de la Organización de las Naciones Unidas "Transformar nuestro mundo: la Agenda 2030 para el Desarrollo Sostenible" (25 de septiembre de 2015, Ref.: A/RES/70/1). Accesible en: https://unctad.org/system/files/official-document/ares70d1_es.pdf.

Directiva 2000/43/CE del Consejo, de 29 de junio de 2000, relativa a la aplicación del principio de igualdad de trato de las personas independientemente de su origen racial o étnico. Accesible en: https://eur-lex.europa.eu/legalcontent/ES/ALL/?uri=celex\%3A32000L0043.

Directiva 2000/78/CE del Consejo, de 27 de noviembre de 2000, relativa al establecimiento de un marco general para la igualdad de trato en el empleo y la ocupación. Accesible en: https://eur-lex.europa.eu/legalcontent/ES/ALL/?uri=CELEX:32000L0078.

Directiva 2003/88/CE del Parlamento Europeo y del Consejo, de 4 de noviembre de 2003, relativa a determinados aspectos de la ordenación del tiempo de trabajo. Accesible en: https://eur-lex.europa.eu/legalcontent/es/ALL/?uri=CELEX:32003L0088.

Resolución del Parlamento Europeo, de 4 de julio de 2017, sobre las condiciones laborales y el empleo precario (2016/2221(INI). Accesible en: https://www.europarl.europa.eu/doceo/document/TA-8-2017-0290_ES.html.

Resolución del Parlamento Europeo, el Consejo y la Comisión de 17 de noviembre de 2017 "Pilar europeo de derechos sociales" (Ref: 2016/2095(INI) Accesible en: https://www.europarl.europa.eu/doceo/document/TA-8-20170010_ES.html.

Constitución Española. Accesible en: https://www.boe.es/buscar/act.php?id=BOE-A-1978-31229.

Ley Orgánica 6/1985, de 1 de julio, del Poder Judicial. Accesible en: https://www.boe.es/buscar/act.php?id=BOE-A1985-12666.

Ley Orgánica 3/2007, de 22 de marzo, para la igualdad efectiva de mujeres y hombres. Accesible en: https://www.boe.es/buscar/act.php?id=BOE-A-2007-6115.

Ley 52/1974, de 19 de diciembre, General de Cooperativas. Accesible en: https://www.boe.es/buscar/doc.php?id=BOEA-1974-2040.

Ley 3/1987, de 2 de abril, General de Cooperativas. Accesible en: https://www.boe.es/buscar/doc.php?id=BOE-A-1987$\underline{8685}$.

Ley 27/1999, de 16 de julio, de Cooperativas. Accesible en: https://www.boe.es/buscar/doc.php?id=BOE-A-199915681.

Ley 39/1999, de 5 de noviembre, para promover la conciliación de la vida familiar y laboral de las personas trabajadoras. Accesible en: https://www.boe.es/buscar/act.php?id=BOE-A-1999-21568.

Ley 62/2003, de 30 de diciembre, de medidas fiscales, administrativas y del orden social. Accesible en: https://www.boe.es/buscar/doc.php?id=BOE-A-2003-23936.

Ley 36/2011, de 10 de octubre, reguladora de la jurisdicción social. Accesible en: https://www.boe.es/buscar/act.php?id=BOE-A-2011-15936.

Real Decreto Legislativo 521/1990, de 27 de abril, por el que se aprueba el texto articulado de la Ley de Procedimiento Laboral. Accesible en: https://www.boe.es/buscar/doc.php?id=BOE-A-1990-9943.

Real Decreto 136/2002, de 1 de febrero, por el que se aprueba el Reglamento del Registro de Sociedades Cooperativas. Accesible en: https://www.boe.es/buscar/doc.php?id=BOE-A-2002-3019. 
Real Decreto Legislativo 1/2013, de 29 de noviembre, por el que se aprueba el Texto Refundido de la Ley General de derechos de las personas con discapacidad y de su inclusión social. Accesible en: https://www.boe.es/buscar/doc.php?id=BOE-A-2013-12632.

Real Decreto Legislativo 2/2015, de 23 de octubre, por el que se aprueba el texto refundido de la Ley del Estatuto de los Trabajadores. Accesible en: https://www.boe.es/buscar/act.php?id=BOE-A-2015-11430. 